\title{
TERRACOTAS ARQUITECTÓNICAS DEL SANTUARIO DE LA ENCARNACIÓN (CARAVACA DE LA CRUZ, MURCIA)
}

\author{
POR \\ SEBASTIÁN F. RAMALLO ASENSIO. \\ Departamento de Prehistoria, Arqueologia, Historia Antigua e Historia Medieval \\ Universidad de Murcia.
}

APÉNDICE DE ESTUDIO MINERALÓGICO

POR

\author{
RAFAEL ARANA CASTILLO \\ Universidad de Mureia
}

\begin{abstract}
RESUMEN
En este trabajo se analiza un conjunto de 61 placas arquitectónicas y 9 antefijas procedentes del santuario de La Encarnación (Caravaca, Murcia). Las placas presentan decoración en un doble registro con palmetas circunscritas en la parte superior y un doble friso de palmetas de siete pétalos alternando con flores de loto, opuesto por su base, y separado por una fila de espirales en horizontal. Las antefijas reproducen los bustos de sátiros y ménades. Se trata de un material importado que tiene en la Peninsula Itálica sus paralelos más inmediatos. Se fechan en el siglo II a. C. y documentan un proceso de monumentalización precoz de un viejo santuario ibérico, impulsado seguramente por la propia Roma.
\end{abstract}

\section{SUMMARY}

In this paper a group of architectural terracottas discovered during excavations at the lberian Sanctuary in La Encarnación (Caravaca, Spain) are studied. The revetment plaques are decorated with a double row of palmettes and lotus-flowers placed back to back, and separated by a row of S-spirals. The inner edge has a cyma with a pattern of five lobed palmettes, each in a round topped frame by a band with scrolled terminals at the base of the palmette. The antefixes representing a young satyr's head with ruffled hair and maenad's head framed by a wreath of vine-leaves. A nebris is tied around his neck. This material is imported from Italy and it is dated in the 2 nd century B.C. 
El santuario de La Encarnación se halla situado en el actual término municipal de Caravaca de la Cruz, al noroeste de la provincia de Murcia, unos $100 \mathrm{Km}$. en línea recta al NO de Cartagena. Hasta ahora las excavaciones han puesto al descubierto dos edificios de culto de distintas dimensiones y tipologia denominados respectivamente como templo A, el de menores dimensiones, arrasado hasta la última hilera de sus cimientos y parcialmente visible y vaciado cuando iniciamos nuestras excavaciones, y el templo B, de mayores dimensiones y que en su estadio final adopta el aspecto de un templo octóstilo, jónico y pseudodiptero (fig. 1).

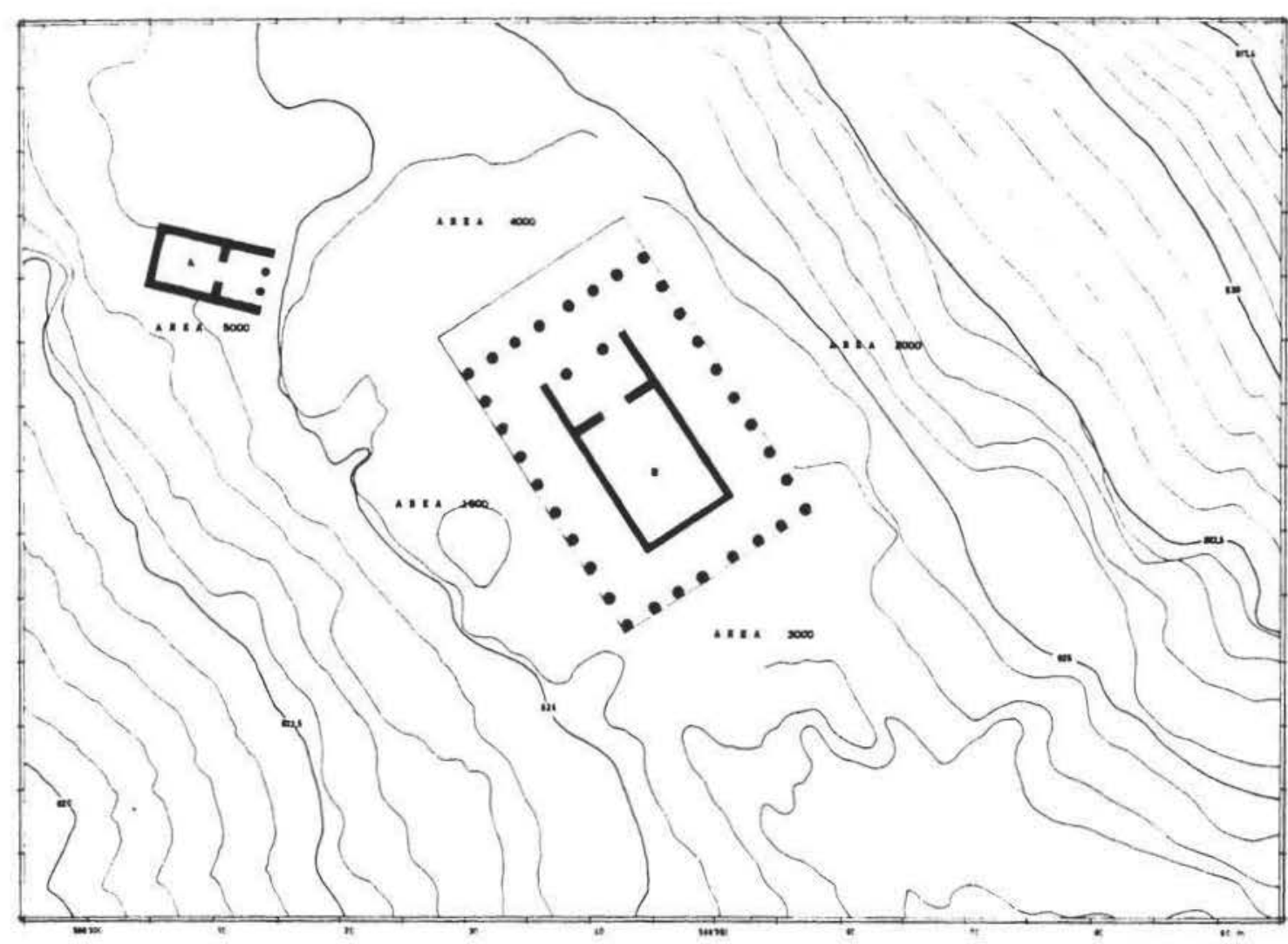

Figura 1.- Santuario de La Encarnación, Caravaca, Murcia. Ubicación de los templos A y B sobre la topografia del Cerro de La Ermita. E. aproximada 1:750.

Las campañas de excavación se desarrollan de forma sistemática desde 1989 y, a pesar de las profundas remociones $\mathrm{y}$ alteraciones que han afectado al primitivo santuario - transformado en una ermita cristiana en el siglo XVI y modificada durante los siglos siguientes por la adición de nuevas construcciones, adosadas al edificio original construido sobre las paredes en opus quadratum de la cella del templo B-, hemos podido recuperar gran parte del material 
arquitectónico y elementos de uso cultual que van permitiendo una aproximación a su realidad histórica. ${ }^{\prime}$

De todo este conjunto, se analiza en este trabajo un abundante lote de material ornamental que incluye terracotas arquitectónicas, formadas por placas de revestimiento ( 61 ejemplares) y antefijas. Procede en su totalidad del denominado Cerro de La Ermita que constituye el centro de un importante complejo arqueológico ubicado a ambas márgenes del río Quipar, y cuyas trazas de ocupación más antiguas se remontan al Paleolítico Medio. Durante la Edad del Bronce se constata ya un hábitat estable en el Cerro de la Placica de Armas, mientras que los poblados ibéricos ocupan sucesivamente los Cerros de Villares y Villaricos que, en cierto modo, enmarcan el Cerro de La Ermita como auténtico centro de culto individualizado de los restantes, pero en estrecha conexión con ellos (Ramallo, 1992, 31 ss.).

\section{PLACAS DE REVESTIMIENTO}

El material más abundante dentro de este apartado está constituido por placas de revestimiento (fig. 2). Todos los ejemplares recuperados pertenecen a un mismo tipo y modelo aunque con arcillas de características externas diferentes. Se trata de un tipo de placa de revestimiento compuesta por un caveto decorado con un friso de cinco palmetas de tres pétalos, circunscritas individualmente por cintas redondeadas terminadas en espiral; un cordón en relieve de sección semicircular separa este primer registro decorativo del motivo central formado por un doble friso, enfrentado por su base, de palmetas de siete pétalos alternando con flores de loto de tres hojas que brotan desde un grueso cáliz acampanado, dispuestos en direcciones contrapuestas y separados por una fila de espirales en S colocadas en horizontal. Sobre el friso superior se inscriben dos palmetas enmarcadas por tres flores de loto y dos semipalmetas en los extremos mientras que en el friso inferior, invertido, se desarrollan tres palmetas encuadradas por dos flores de loto y en los extremos otras tantas seccionadas longitudinalmente por la mitad. El extremo inferior de la placa está recortado siguiendo en cierto modo los contornos impuestos por las hojas de la flor de loto. Dos orificios de sujeción de $0,9 / 1 \mathrm{~cm}$. de diámetro están situados generalmente sobre las palmetas circunscritas de los extremos, y otros tres, del mismo diámetro, se distribuyen sobre el friso superior junto a las semipalmetas de los extremos y junto a la flor de loto central. No se han registrado perforaciones sobre el friso inferior.

Dimensiones: $23,2 \mathrm{~cm}$. de anchura; $24,9 \mathrm{~cm}$. de altura y entre 2 y $4 \mathrm{~cm}$. de grosor.

Arcilla: Por su aspecto externo se pueden establecer dos grupos distintos a los que se adscriben todas las terracotas, caracterizados respectivamente por tonos rosaceo-anaranjados, con ligeras matizaciones dentro de esa gama de colores, y otro grupo, minoritario, de tonos grisáceo-oscuros. En ambos casos, las partículas de desgrasante son visibles en superficie al haber desaparecido la posible pintura que las recubría exteriormente.

' Parte del trabajo que aquí se presenta ha sido realizado dentro del proyecto de investigación «El templo romano de La Encarnación (Caravaca, Murcia): un modelo para la documentación del patrimonio histórico-artístico" (PSH 89-21) subvencionado por la Dirección General de Educación y Universidad (CARM). Los trabajos de delineación han sido ejecutados por D. Antonio Martínez Ortega. 

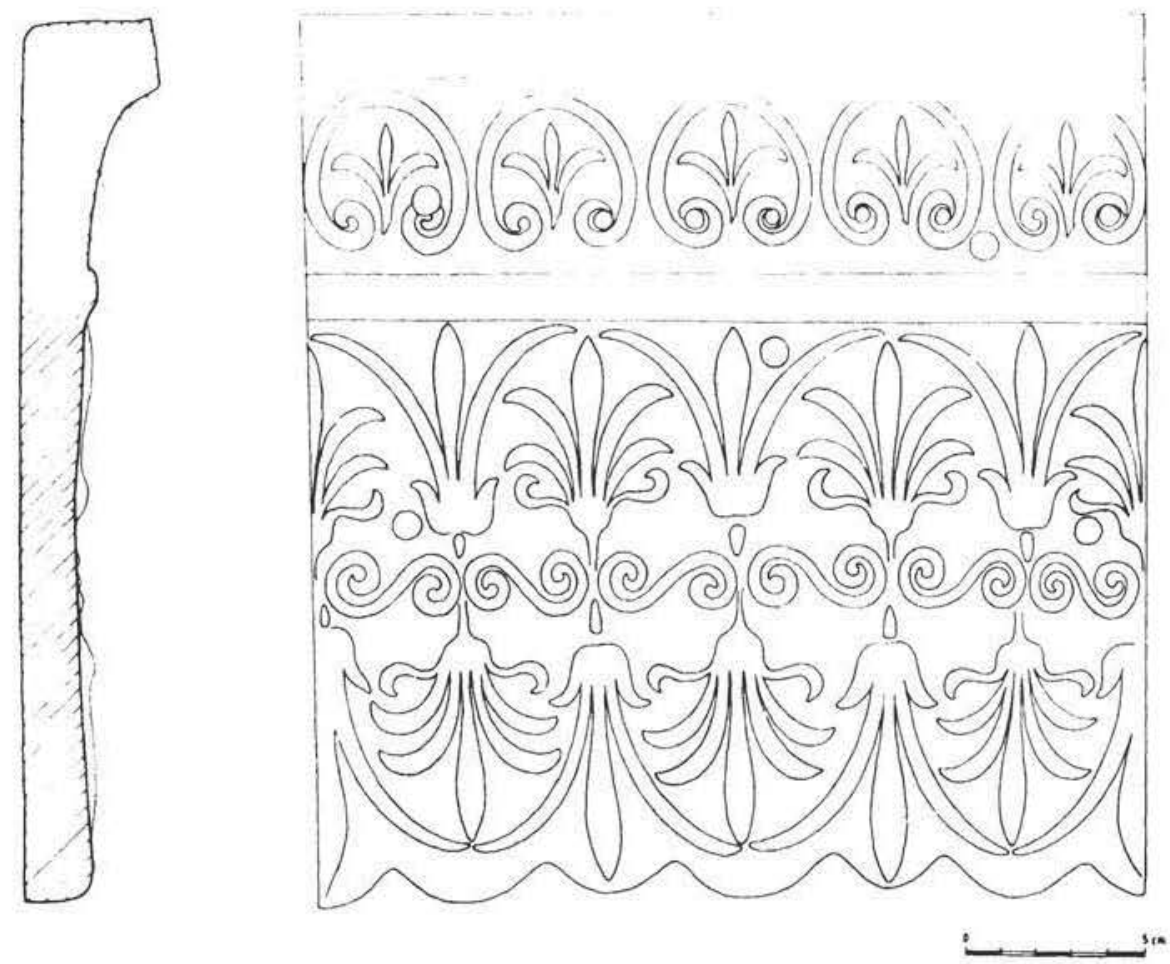

Figura 2.- Restitución de la decoración de la placa arquitectónica a partir de los fragmentos conservados. E. 1:3.

Distribución: En general, las terracotas arquitectónicas aparecen dispersas por todo el Cerro de La Ermita mezcladas entre niveles de arrastre, relleno o colmatación caracterizados por la abundancia de cerámicas ibéricas y escasez de cerámicas propiamente romanas. Algunos fragmentos fueron incluso empleados como cuñas de nivelación en la construcción de determinados sectores de la ermita y dependencias anexas; así hemos recuperado varios fragmentos de placa, fuertemente impregnados de yeso, cal o cemento, al retirar los escombros de las construcciones del siglo XIX (camarín de la virgen, habitaciones, etc.) que se adosaban a la cabecera de la ermita original (área 3000). Algunos fragmentos han aparecido junto al denominado Templo A (área 5000), otros junto a las cimentaciones de construcciones modernas situadas al norte del templo (área 4000), también en el lateral oeste del templo sobre el estrato de nivelación del terreno circundante al edificio en un estrato de vertido reciente, aunque la mayor parte procede del potente nivel de arrastre que discurre sobre la ladera oriental del cerro, en el área que hemos denominado 2000.

En el cuadro adjunto se insertan, a modo de catálogo, los fragmentos más significativos. En la descripción de las piezas se han seguido los siguientes parámetros: número de inventario que está formado por tres cifras que permiten identificar, sucesivamente, la zona de localización (área, corte, estrato), código del material ( 810 para las terracotas arquitectónicas y 812 


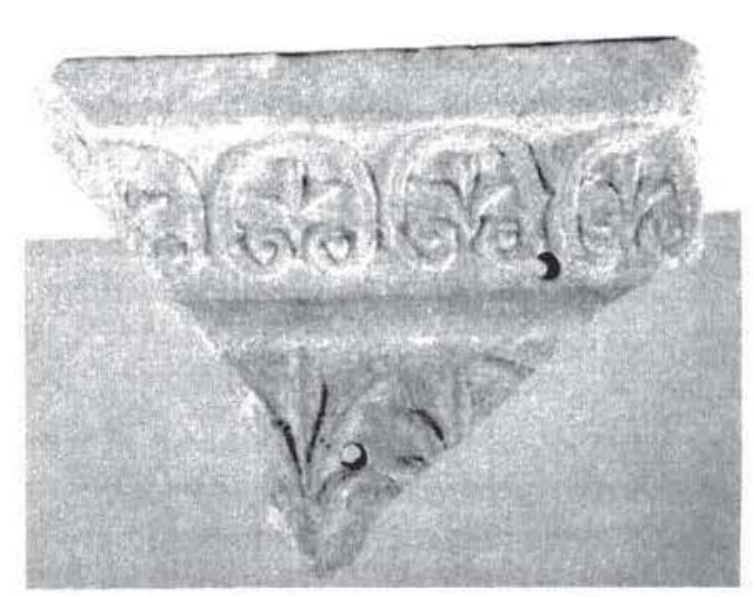

Figura 3. Fragmento de placa hallado en las excavaciones de urgencia de 1981 (L-1000/810-1).

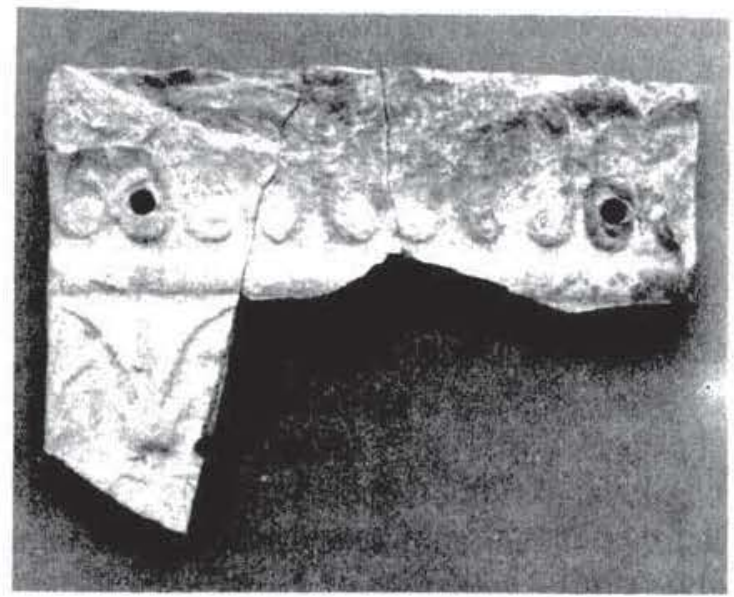

Figura 4. Fragmento de placa hallado en las excavaciones de 1991 (L-4200/810-1).

para las antefijas) y número de orden; dimensiones máximas de la pieza, expresadas en milimetros (longitud, anchura y grosor máximo y minimo); y finalmente descripción del fragmento conservado.

\section{Catálogo}

\begin{tabular}{|ccccll|}
\hline Proceden. & Long. & Anch. & GMax. & GMin. & Ubicación \\
\hline $3000 / 810-1$ & 69 & 67 & 23,2 & 19 & Ang. inf. izq. \\
$1000 / 810-1$ & 154 & 195 & 39,4 & 15 & Registro sup. \\
$1000 / 810-2$ & 50 & 87 & 35 & 20 & Ang. sup. izq. \\
$1000 / 810-3$ & 109 & 81 & 24,6 & 19,2 & Ang. inf. izq. \\
$0001 / 810-1$ & 94,6 & 89,2 & 19,3 & 17,2 & Ang. inf. der. \\
$0001 / 810-2$ & 86,7 & 64,2 & 18,8 & 16,3 & Friso inf. \\
$1300 / 810-1$ & 89 & 84 & 19 & 18 & Ang. inf. der. \\
$3000 / 810-2$ & 120,6 & 109,8 & 24,3 & 17 & Ang. inf. izq. \\
$0001 / 810-4$ & 76,7 & 59,6 & 21,1 & 20 & Ang. inf. der. \\
$3000 / 810-3$ & 103,9 & 61,5 & 17 & 17 & Central \\
$1400 / 810-4$ & 96,1 & 101 & 31 & 17,8 & Ang. sup. izq. \\
$1400 / 810-5$ & 67 & 49 & 19 & 17 & Central \\
$1400 / 810-1$ & 83,1 & 80,2 & 20,1 & 18,3 & Central \\
$1400 / 810-2$ & 67,8 & 60 & 22,3 & 19 & Ang. inf. der. \\
$1400 / 810-3$ & 108,3 & 87,9 & 20,8 & 17,3 & Ang. inf. der. \\
$5001 / 810-1$ & 95,2 & 78,2 & 21 & 15,6 & Lat. izq. \\
$2202 / 810-1$ & 66 & 69 & 18 & 17 & Central sup. \\
$2404 / 810-1$ & 54,7 & 50,6 & 36,7 & 21,5 & Registro sup. \\
$3007 / 810-1$ & 41,6 & 81,9 & 21 & 10,3 & Ang. sup. izq. \\
$4100 / 810-1$ & 93,4 & 78,6 & 34 & 18,6 & Registro sup. \\
\hline
\end{tabular}




\begin{tabular}{|c|c|c|c|c|c|}
\hline Proceden. & Long. & Anch. & GMax. & GMin. & Ubicación \\
\hline $4200 / 810-1$ & 169 & 235 & 28,6 & 19 & Perfil completo \\
\hline $2000 / 810-1$ & 113,8 & 162 & 22 & 17 & Central \\
\hline $2000 / 810-2$ & 54,6 & 95,6 & 19 & 17,4 & Central \\
\hline $2000 / 810-3$ & 73,5 & 113,5 & 20 & 17 & Central \\
\hline $2000 / 810-4$ & 82,3 & 125,7 & 39,7 & 19,6 & Ang. sup. der. \\
\hline $2000 / 810-5$ & 105 & 92,4 & 22,3 & 19 & Ang. inf. der. \\
\hline $2000 / 810-6$ & 61,3 & 97,5 & 37,9 & 20,3 & Ang. sup. der. \\
\hline $2000 / 810-7$ & 81,2 & 80 & 19,9 & 18 & Ang. inf. der. \\
\hline $2000 / 810-8$ & 58,6 & 64,1 & 19,7 & 17,5 & Lateral izq. \\
\hline 2000/810-9 & 96 & 115,6 & 18,2 & 15,4 & Ang. inf. der. \\
\hline $2000 / 810-10$ & 73 & 66,5 & 21,6 & 18,6 & Central \\
\hline $2000 / 810-11$ & 84 & 70,2 & 17,8 & 16,9 & Lateral der. \\
\hline $2000 / 810-12$ & 98,1 & 93,3 & 21,2 & 19 & Ang. inf. der. \\
\hline $2000 / 810-13$ & 49 & 83,2 & 18,8 & 18,8 & Ang. inf. der. \\
\hline $2000 / 810-14$ & 64 & 82,6 & 18 & 15,3 & Central \\
\hline $2000 / 810-15$ & 72,6 & 78,1 & 34 & 18,1 & Ang. sup. izq. \\
\hline $2000 / 810-16$ & 49 & 85 & 37,8 & 24 & Ang. sup. der. \\
\hline $2000 / 810-17$ & 70 & 99,8 & 23,8 & 23,8 & Central \\
\hline $2000 / 810-18$ & 63,7 & 80 & 19,7 & 16,4 & Central \\
\hline $2000 / 810-19$ & 112 & 141 & 21,7 & 20,6 & Central \\
\hline $2000 / 810-20$ & 46 & 65,3 & 18,1 & 18,1 & Central \\
\hline $2000 / 810-21$ & 50 & 61 & 18,9 & 18,9 & Central inf. \\
\hline $2000 / 810-22$ & 68,6 & 84,7 & 22,2 & 21,5 & Lateral der. \\
\hline $2000 / 810-23$ & 64,7 & 86,3 & 34,1 & 18,4 & Ang. sup. izq. \\
\hline $2000 / 810-24$ & 75 & 186 & 31 & 16,6 & Registro sup. \\
\hline $2000 / 810-25$ & 85 & 101 & 19,9 & 16,6 & Central inf. \\
\hline $2000 / 810-26$ & 87,6 & 121,3 & 22,1 & 18,6 & Central sup. \\
\hline $4229 / 810-1$ & 127 & 173 & 20 & 17 & Friso inf. \\
\hline $4229 / 810-2$ & 60 & 71 & 17 & 2 & Registro sup. \\
\hline $1000 / 810-4$ & 58 & 104 & 34 & 15 & Registro sup. \\
\hline $1000 / 810-5$ & 78 & 56 & 19 & 12 & Central \\
\hline $2000 / 810-27$ & 61 & 13,2 & 34 & 19 & Ang. sup. izq. \\
\hline $5138 / 810-1$ & 66 & 70 & 22 & 19 & Ang. sup. der. \\
\hline $5140 / 810-1$ & 69 & 64 & 34 & 19 & Ang. sup. izq. \\
\hline $2501 / 810-3$ & 64 & 96 & 18 & 18 & Ang. inf. der. \\
\hline $2501 / 810-4$ & 93 & 90 & 18 & 17 & Central. \\
\hline $2500 / 810-1$ & 96 & 68 & 18 & 18 & Central \\
\hline $2500 / 810-2$ & 58 & 63 & 18 & 10 & Central \\
\hline $2501 / 810-1$ & 126 & 88 & 18 & 17 & Lateral der. \\
\hline $2501 / 810-2$ & 62 & 75 & 18 & 17 & Central \\
\hline $4229 / 810-3$ & 52 & 59 & 20 & 19 & Ang. sup. der. \\
\hline
\end{tabular}




\section{Análisis de la decoración}

Individualmente, el motivo representado sobre estas placas de revestimiento se repite en distintas facetas artísticas de ámbito greco-etrusco al menos desde fines del siglo VI-inicios del siglo $\mathrm{V}$ a.C. Así, las palmetas alternando con flores de loto, que constituyen el tema central de las terracotas de Caravaca, se muestra, ya plenamente formado, sobre una laminita de bronce procedente de Vulci y conservada en el Museo de Villa Giulia (sala V, vitr. 4). En ambiente plenamente griego, vemos también las palmetas encuadradas por flores de loto sobre una tegula hiposcópica de Locri depositada en el Museo de Reggio di Calabria (Gullini, 1980, lám. XIX,6), y también como decoración pintada en el templo C de Selinunte, aún dentro del siglo VI a.C. (Wikander, 1986, 41-42). El motivo desarrollado sobre un único friso horizontal se repite también sobre una serie de placas cerámicas pintadas del santuario etrusco de Veií, con flores de loto estilizadas rematadas en cintas en espiral (Stefani, 1951, lám. D).

Con las placas arquitectónicas realizadas a molde, el repertorio de paralelos se amplía considerablemente tanto desde el punto de vista geográfico como cronológico. El tema se manifiesta de dos formas distintas. Las placas más antiguas y generalmente de mayores dimensiones con los motivos citados pertenecen en su mayor parte a ciudades de clara raigambre etrusca (fig. 5). En Caere vemos el doble friso con palmetas de once pétalos y flores de loto separados por una banda de espirales en horizontal sobre placas de grandes dimensiones $(61 / 65 \mathrm{~cm}$. x 47/48 cm.), asociados a un caveto de estrígilos y fechadas a finales del siglo IV y siglo III a.C. (Andren, 1940, lám. 19). En este mismo contexto hay que situar también las placas del «Ara della Regina" con idéntico esquema decorativo (Cataldi, 1986, fig. 357). Similar esquema, aunque con palmetas de nueve pétalos y con mayor anchura que longitud (c. $60 \times 43 \mathrm{~cm}$.), se repite sobre placas del templo de Belvedere de Orvieto, con estrígilos asimismo sobre el registro superior (Andren, 1940, lám. 70,1) y, en cierto modo, en Minturnae, con la decoración de la placa dividida en tres registros (Johnson, 1935, 87, fig. 44). Una variante, con espirales entrelazadas, nos ofrece una placa del Antiquarium de los Museos Capitolinos, seguramente procedente del territorio de Bolsena, fechada entre fines del siglo IV y la primera mitad del siglo III a.C. (Colini, 1935, lám. XXVI,3), composición que se repite sobre tres placas del Museo Nacional de Copenhague (Breitenstein, 1941, lám. 95). Bajo las cimentaciones del templo B de Pietrabbondante hallamos una decoración de estas características, si bien con las flores de loto más desarrolladas, asociadas a placas decoradas con dos grandes palmetas en diagonal y espirales en el sentido opuesto, fechadas, en parte por contexto arqueológico entre los siglos III-II a.C. (Niro, 1980). Por otra parte, en Todi, placas muy fragmentadas con palmetas y flores de loto, se insertan en el grupo b, que se paraleliza con las placas de Orvieto (Falconi, 1977).

En el santuario de Minerva en Punta della Vipera (Sta. Marinella) sobre placas fechadas hacia mediados del siglo IV a.C., palmetas de siete pétalos lanceolados y cáliz triangular alternan con flores de loto de hojas divergentes y tres pistilos centrales bajo una cornisa estrigilada (Stopponi, 1979, fig. 3, 4 y Torelli, 1967). Muy próximas estilisticamente a las placas de Santa Marinella se hallan las del santuario etrusco de Pyrgi, encuadrables ya dentro de su segunda fase (inicios del siglo IV-siglo III a.C.), y caracterizadas por una cornisa estrigilada con pequeñas vainas cóncavas y con núcleo de campanillas en las flores de loto del friso inferior. La existencia de algunas placas y fragmentos con corte oblicuo han llevado a proponer su utilización para el revestimiento de marcos de puertas (Pyrgi, 1970, fig. 156).

Finalmente, dentro de esta serie de placas arquitectónicas caracterizada por una cornisa 

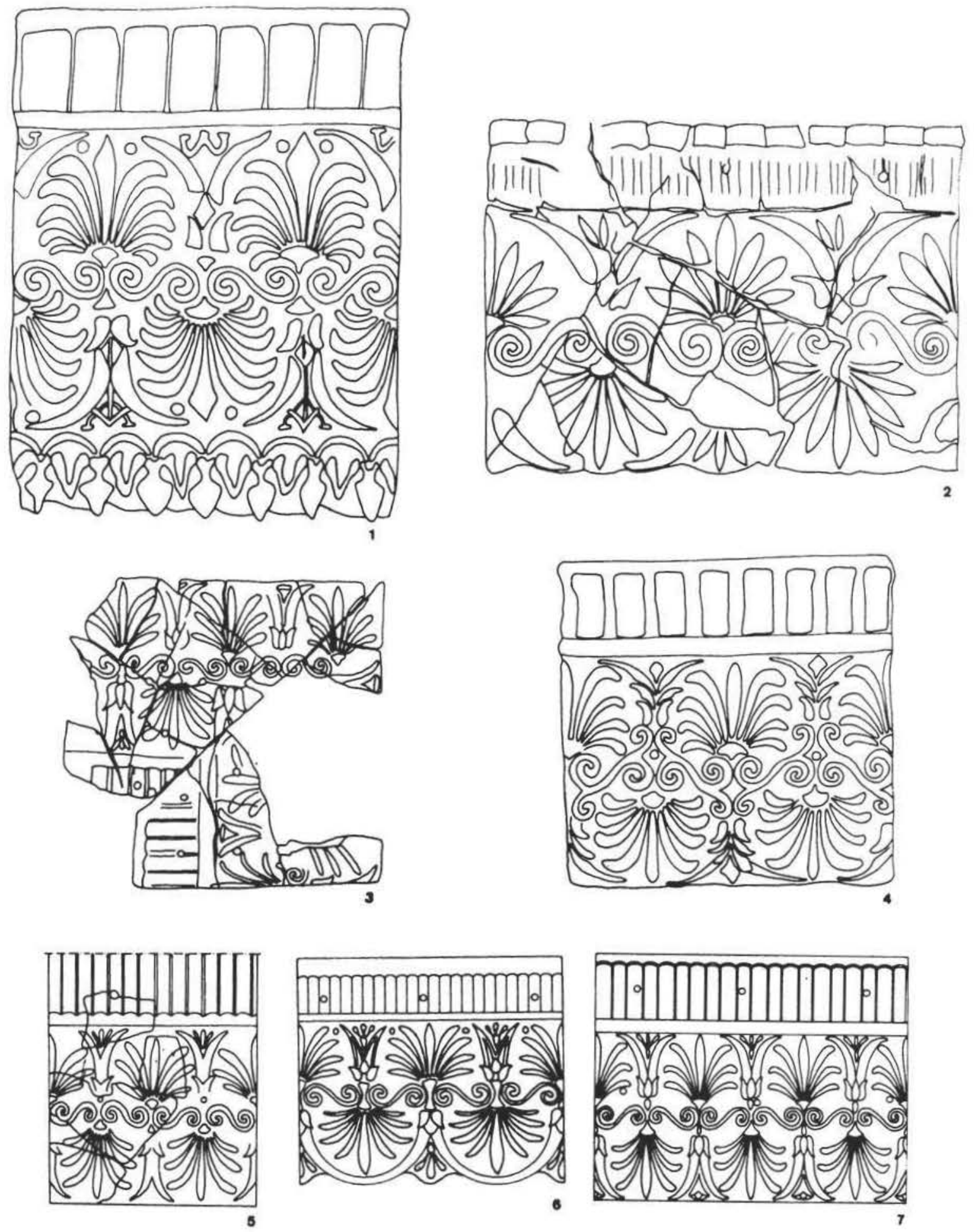

Figura 5.-Paralelos para el friso central con palmetas y flores de loto de La Encarnación: 1, Caere. 2, Orvieto. 3, Pyrgi. 4, Roma (Antiquarium dei Musei Capitolini). 5, Punta della Vipera. 6, Cosa. 7, Pyrgi. 
con estrigilos en el registro superior y el doble friso de palmetas alternando con flores de loto en el inferior, hay que recordar la serie proporcionada por las excavaciones de Cosa. El Capitolium, en el que ha sido definido por sus excavadores como cuarto periodo de la decoración, segunda reparación, ofrece un tipo de placa con palmetas de nueve pétalos y flores de loto de hojas muy estilizadas en el friso superior, mientras que en el inferior estas mismas hojas se unen entre si enmarcando por completo la palmeta y condicionando el desarrollo del borde inferior de la placa. Sus dimensiones además son tan sólo algo mayores que las de las piezas de Caravaca, mientras que cronológicamente esta fase se sitúa a finales del primer cuarto del siglo I a.C. (Richardson, 1960, lám. XLV,2).

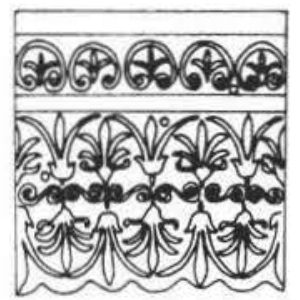

(1)

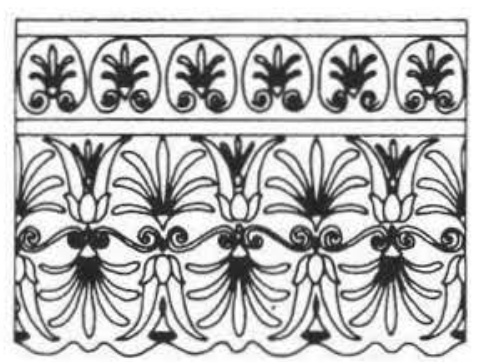

(1)

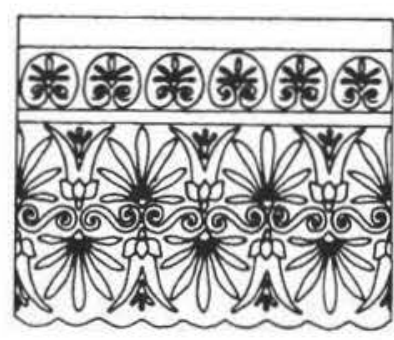

(1)
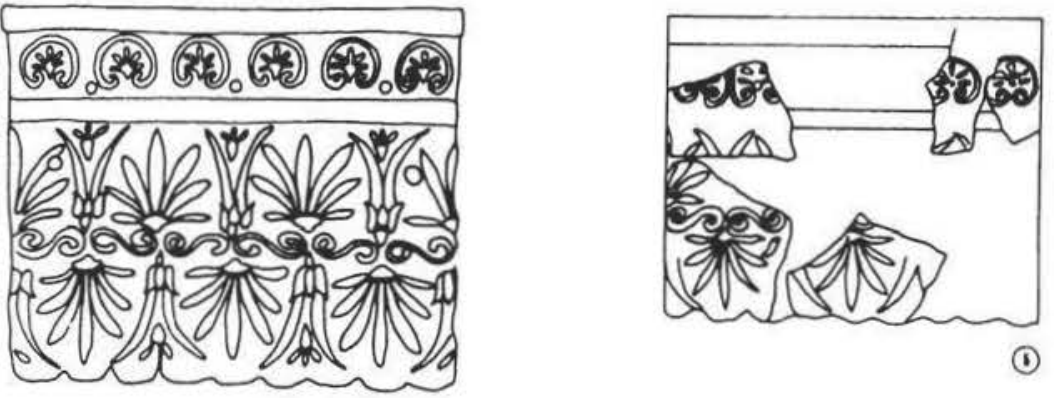

(1)

(1)

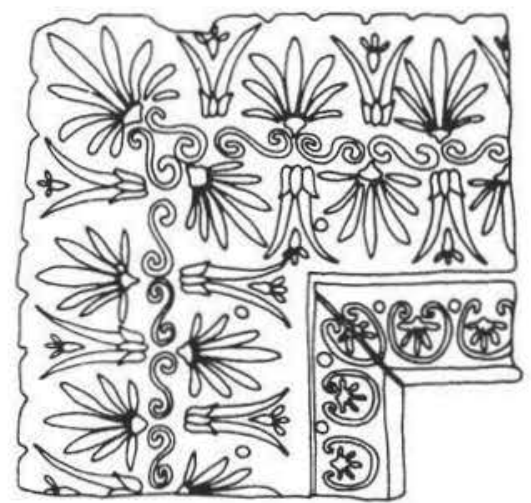

(1)

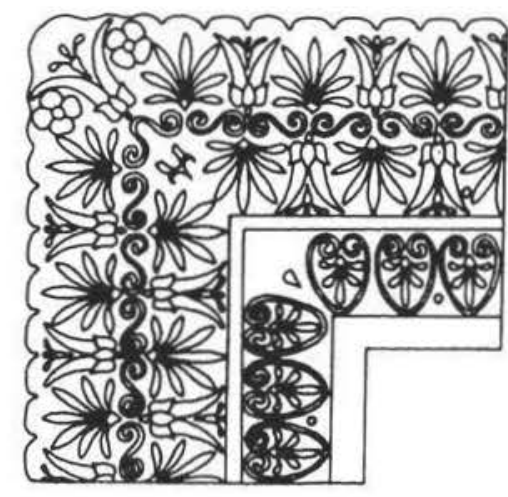

(1)

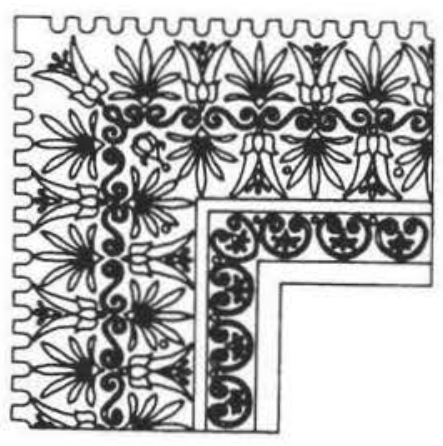

(1)

Figura 6.--Principales paralelos para las placas de La Encarnación: 1, La Encarnación. 2, Pyrgi. 3, Lanuvium. 4, Lo Scasato (Cività Castellana). 5, Ardea. 6, Lo Scasato (Cività Castellana). 7, Cosa. Capitolium, decoración original. 8, Cosa. Capitolium, 3. ${ }^{\text {er }}$ periodo de la decoración. 
En cualquier caso, conocemos también otra abundante serie donde se reproduce el mismo esquema compositivo con mayor fidelidad, y en dos registros superpuestos con idénticos motivos a los desarrollados en las placas de terracota de Caravaca (fig. 6). Una placa del santuario oriental de Lanuvio, fechada dentro del siglo III, nos ofrece un caveto decorado con seis palmetas de seis pétalos circunscritas por una cinta ovalada rematada en espiral, separado por un cordón en relieve del registro central, decorado por un doble friso de palmetas de siete pétalos y flores de loto, contrapuestos y separados por una banda de espirales en horizontal (Enea, 1981, D72). Idéntica composición se reproduce sobre placas de Ardea fechadas entre los siglos IV (Grupo I A) y la primera mitad del siglo I a.C. (Grupo III C; Andren, 1932, lám. IV,2, y también, de la Acrópolis, Stefani, 1944-45, fig. 27d y del Templo di Colle della Noce, Ardea, Imagini, 1983, f. 131), con muy pocas variantes entre unas y otras, y en el templo de Lo Scasato (Cività Castellana), en terracotas encuadradas por Andren en su Grupo III, pertenecientes a la segunda mitad del siglo III a.C. (Andren, 1940, lám. 54). Pyrgi nos ofrece de nuevo placas con seis palmetas circunscritas sobre el registro superior y el doble friso con palmetas de siete pétalos y flores de loto en el inferior, así como en Cosa donde destacan proporcionalmente el número de fragmentos de esquina, esto es, en ángulo recto. En esta última ciudad se distribuyen en ejemplares procedentes unos de la decoración original del Capitolium, c. 150 a.C. y otros del tercer periodo de la decoración, primera redecoración, fechado en torno al año 100 a.C., con la principal diferencia en el contorno del borde inferior, ondulado en los ejemplares más antiguos y denticulado en los más modernos. Finalmente completan esta revisión los fragmentos de placa arquitectónica de Norba, tempio maggiore, con palmetas y flores de loto (Sarignoni-Mengarelli, 1901, fig. 21 y Andren, 1940, 386,3) y los del Capitolium de Signae, encuadrados por Andren dentro del Grupo II (siglos IV-III a.C.) con palmetas circunscritas en el registro superior y doble friso de palmetas y flores de loto. Las palmetas de siete pétalos son aquí prácticamente idénticas a las de La Encarnación de Caravaca (Delbruck, 1903, lám. VI,1-2, y Andren, 1940, 404). Otros fragmentos de placas con la misma decoración, aunque de factura algo más descuidada, han sido hallados en Luni y se les ha atribuido una cronologia de los siglos II-I a.C. (Milani, 1885, lám. VII,5). Nuevas variantes se aprecian en placas del templo de Talamón, con los dos frisos de palmetas y flores de loto directamente opuestos por su base, sin línea de espirales (Libertini, 1921 y Talamone, 1982, 66, fig. 70)

\section{Problemas cronológicos}

Desde el punto de vista cronológico, el principal problema que se plantea es la falta de un contexto arqueológico claro que de momento permita asociar este material arquitectónico con cerámicas, monedas $u$ otras producciones bien conocidas que puedan establecer una cronología lo más aproximada posible. Hasta ahora, y dejando a un lado los fragmentos de placa reutilizados en la construcción de los distintos edificios que constituyen el centro de culto moderno, la mayor parte del material ha sido hallado en los estratos de relleno o arrastre que prácticamente rodean el templo por sus cuatro lados, y sobre todo en la ladera este del cerro (UE.2000) asociadas a material ibérico seguramente de los siglo III-II a.C. procedente de la amortización y desmonte de las estructuras precedentes a la construcción del templo en su aspecto más monumental, y tal como se nos ha conservado hoy dia. De momento, sí parece clara la inutilización de este tipo de material en la primera mitad del siglo II d.C., amortización que se constata con el hallazgo de algunos fragmentos de placa en el nivel de abandono y 
colmatación de las canteras, situadas en la pendiente sureste del cerro de donde con toda probabilidad se extrajo la piedra para la construcción del edificio monumental y de la situada al SO del templo A, junto al actual camino de acceso a la ermita.

Por otra parte, queda clara, tras los análisis estilisticos y sobre todo mineralógicos de las arcillas utilizadas, la importación del material, con toda seguridad a través del puerto de Carthago Nova, desde algún punto de Italia, donde la cronología misma de este material está en muchos casos sujeta a discusión. Se ha llamado la atención sobre la estereotipación y reproducción mecánica de los mismos tipos en periodos de tiempo muy amplios, de forma que la datación por criterios estilísticos, sobre todo en el caso de las placas que aqui nos ocupa, debe ser necesariamente amplia (Strazzula, 1977, 41). Es evidente, que desde el punto de vista estilístico, como ya hemos señalado más arriba, los paralelos más próximos a las placas de Caravaca proceden de Pyrgi, Lanuvio, Cività Castellana, Ardea, Cosa, Nemi, Segni y Norba. Ahora bien, si revisamos la cronología dada a estos conjuntos observamos cómo existen divergencias entre los distintos investigadores que se han ocupado del tema. El caso más significativo, por ser el que de momento ofrece uno de los soportes arqueológicos y estratigráficos más precisos, es el de las terracotas de Cosa, colonia fundada en el 273 a.C., donde las placas con registro de palmetas circunscritas (o estrígilos) y doble friso de palmetas de siete pétalos y flores de loto del Capitolium, se ubican entre el 150 a.C. para la decoración original y fines del primer cuarto del siglo I a.C., para el cuarto período de la decoración, segunda reparación (Richardson, 1960). Posteriormente, se ha sugerido una datación más alta para la construcción del Capitolium, quizás vinculada al final de la Segunda Guerra Púnica y a la segunda deducción colonial del 197 a.C., al tiempo que se ha cuestionado la periodización casi mecánica en lapsos de 25 años para las sucesivas redecoraciones o reparaciones del templo (Strazzula, 1977, 43). En cualquier caso, parece clara la ubicación de este conjunto de terracotas a lo largo del siglo II y, todo lo más, a inicios del siglo I a.C.

Más problemática incluso es la datación de las terracotas de Cività Castellana, hoy identificada con Falerii, principal centro de los faliscos, cuyas terracotas, en el caso concreto del tempio dello Scasato que aquí más nos interesa, se ubican entre fines del siglo IV y los siglos II-I a.C., aunque para Torelli las terracotas de los grandes templos urbanos de Scassato y de Vignale serían anteriores a la destrucción del 241 a.C. $(1974,101)$. Andren las encuadra dentro de su Grupo III que corresponde a la segunda mitad del siglo III (Andren, 1940, 142). Por otra parte, en base a la identificación Cività Castellana=Falerii y a la conocida destrucción de la ciudad a manos de los romanos en el 241 a.C., algunos autores sitúan estas terracotas dentro de la primera mitad del siglo III, mientras que otros, en base sobre todo al eclecticismo de las figuras y a las características de la decoración a molde las ubican ya dentro del siglo II a.C. (Strazzula, 1977, 44). En este sentido, Richardson, en el análisis de las terracotas de Cosa de tipo similar, encuadra las de Cività Castellana en el segundo tercio del siglo II a.C. Strazzulla (1977, 44-45) en una solución de compromiso, señala tres posibilidades distintas: que todas sean del siglo II a. C., que sean del siglo III a.C., anteriores a la destrucción de Falerii, o bien que el conjunto responda a varias fases de las cuales la última, limitada a las placas a molde, corresponda ya al siglo II a.C. Las placas de Pyrgi son comúnmente ubicadas entre los siglos IV-III a.C. (Pirgy, 1970; Strazzula, 1980, n. ${ }^{\circ} 37$ ), mientras que las de Segni, sin duda las más próximas estilísticamente a las de Caravaca, parece que se pueden situar, al igual que las de Luni, ya dentro del siglo II a.C. (Strazzula, 1980, n. 59; Richardson, 1960). En cualquier caso, la práctica totalidad de las placas con los motivos descritos se han de ubicar en un abanico cronológico que cubre 
los siglos III-II a.C. con una posible prolongación, tan sólo en algunos casos, en el siglo I a.C. Consecuentemente, y si junto al análisis estilistico relacionamos el material cerámico de Caravaca con otros elementos arquitectónicos y votivos vinculados al templo, debemos situar las placas exhumadas en el discurrir del siglo II a.C. o, todo lo más, en los primeros años del siglo I a.C. En esta dirección, y si seguimos criterios estilisticos, es evidente una mayor esquematización de los distintos motivos que componen el conjunto de la decoración en relación a los modelos italianos. Esta diferencia se plasma en el número de palmetas circunscritas, cinco en nuestro caso y seis en casi todos los paralelos aportados (excepto cinco en el templo de Diana de Nemi), y se manifiesta sobre todo en la terminación de las flores de loto que en nuestro caso se reducen a un cáliz compacto donde apenas se vislumbran los tres sépalos y a las esquematizadas hojas que de él brotan, mientras que ya han desaparecido los tres pistilos o las campaniIlas de las placas de Pyrgi, Cività Castellana o Cosa, por citar tan sólo algunos de los ejemplos.

Es curioso observar cómo el motivo representado en las placas es sobre todo caracteristico de edificios sacros datados en el siglo III o en la primera mitad del siglo II a.C. y cómo desaparece, o más bien es parcialmente sustituido en la decoración arquitectónica de los templos de la segunda mitad del siglo 11 y del siglo I a.C., en que se generalizan las placas decoradas con dos grandes palmetas de nueve pétalos dispuestas en diagonal y opuestas entre si, con dos grandes espirales en S perpendiculares a ellas que ocupan el resto del campo. El segundo motivo más difundido presenta una doble fila de palmetas de cinco pétalos, orientadas alternativamente hacia arriba y hacia abajo, rodeadas por una cinta plana y entrelazadas por volutas en espiral. Ejemplos de estos modelos muy significativos y bien datados nos los proporcionan el santuarío de Juno en Gabii, c. 160/150 a.C. (Dupré, 1982, págs. 132 y ss.) y en Luni, especialmente el Capitolium y el Gran Templo, post. 177 a.C. (Forte, 1991, ff. 1-7; y Forte, $1992,185 \mathrm{ss}$.). En nuestro caso, el motivo del doble friso de palmetas alternando con flores de loto se relaciona más con las terracotas de tradición etrusca de fines del siglo IV y siglo III a.C.

\section{Procedencia}

Respecto a la procedencia de la producción parece fuera de toda duda su origen en el área centro itálica (fig. 7). Es precisamente en el círculo de poblaciones situadas en el área de influencia romana donde hallamos, como ya hemos visto, los paralelos más inmediatos. Por otra parte, la propia naturaleza de la arcilla (vid. anexo) nos indica claramente que se trata de un material manufacturado en origen que se exporta ya terminado y listo para su utilización al centro de destino; hay pues que descartar una posible circulación de moldes hasta talleres urbanos más próximos cual sería la ciudad de Carthago Nova donde se habría podido fabricar una producción de esta naturaleza. En este sentido, es evidente la estrecha relación que existe entre esta ciudad y la población caravaqueña que se manifiesta además en la utilización de los mismos prototipos y modelos en el material arquitectónico (basas, capiteles, cornisas, etc.), trabajados en este caso en piedra local, incluso parece más que probable el desplazamiento de un equipo u officina Carthaginensis para la construcción del templo de La Encarnación, lo que hace también plausible que el material cerámico de revestimiento haya sido transportado desde la ciudad portuaria. En cualquier caso, se trataría de un material muy concreto encargado ya con unos fines y un destino final ya predeterminado pues hay que destacar también la ausencia, de momento, de un material de características similares en la propia Carthago Nova, donde por otra parte, conocemos ya bastante bien, la cultura material de época tardo-republicana. 
Todo ello se relaciona también con el proceso de construcción del templo del cual, placas y antefijas constituyen un elemento importante. Ahora bien, ¿ese material se encarga ya a los centros de producción con unas dimensiones determinadas según el plano elaborado previamente por la officina y los operarios encargados de construir el templo? o, por el contrario, ¿forma parte de todo un "paquete» importado que incluye incluso un determinado modelo arquitectónico donde se expresa la totalidad de la obra?

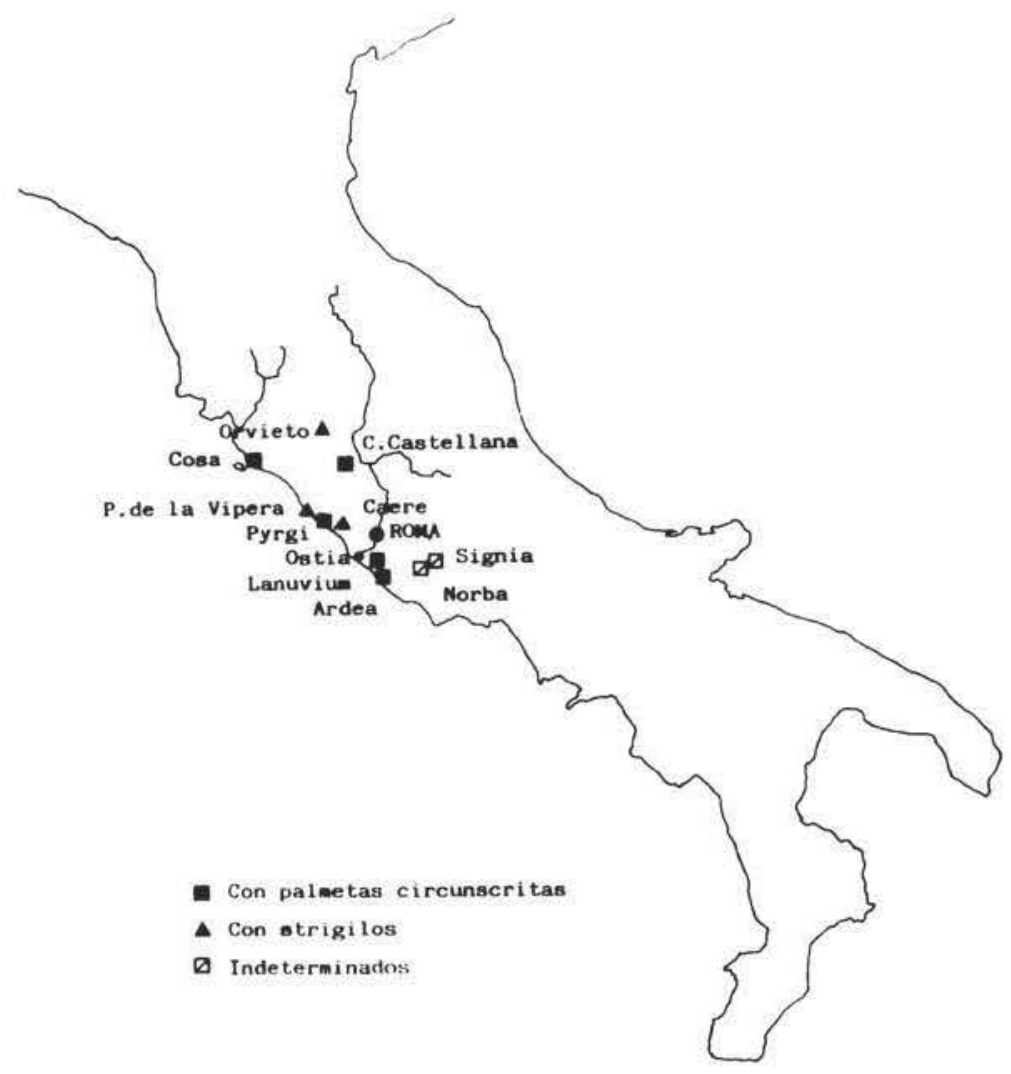

Figura 7.-Distribución geográfica de los paralelos establecidos para las placas arquitectónicas de La Encarnación.

Este fenómeno de importación directa del producto ya elaborado contrasta con lo que se ha podido observar en otras ciudades de la misma Italia, como por ejemplo en el caso concreto de Luni, donde los modelos utilizados en la decoración arquitectónica corresponden de forma precisa con programas decorativos empleados contemporáneamente en la misma Roma, pero sin embargo, los análisis mineralógicos indican una fabricación con arcillas locales (Forte, 1991, 70).

En cualquier caso, la importación del producto contrasta con la idea de ausencia de un comercio marítimo o transalpino para estos productos durante época tardo-republicana (Anselmino, 1981, 214). Por el contrario, y en el caso concreto de Italia, especialmente en el área de la Etruria centro-meridional, sobre todo en una primera fase, la decoración cerámica aparece muy vinculada al propio proceso de construcción del templo e incluso pequeños talleres de coroplastas elaboran su producción a pie de obra (Bedello, 1990, 97 ss.). Es sobre todo a partir 
de inicios del siglo Il con motivo de la reactivación edilicia motivada por el fin de la Segunda Guerra Púnica, cuando se configuran ya las grandes empresas que tienen su principal centro de producción en la propia Roma al mismo tiempo el principal cliente para estos talleres (Strazzula, 1980).

Otro problema distinto afecta a la ubicación de estas placas en el templo. En este sentido, precisamente las reducidas dimensiones de las terracotas de La Encarnación e incluso es más, de muchos de los prototipos descritos con los mismos motivos que las placas de Caravaca, y el hecho de que en algunas localidades se hayan localizado en placas de esquina, han llevado a proponer su utilización para el recubrimiento de los marcos de puertas (Andren, 1940, 142; Pyrgi, 1970, 228) además de para el recubrimiento del columen o gran viga central del techo, para los mutuli o vigas laterales y para la gran viga que corría en los muros de la cella (Richardson, 1960,224). De momento el elevado número de placas con idénticas dimensiones y el mismo motivo parece implicar su pertenencia a un mismo friso que, si consideramos la anchura de cada placa multiplicada por el número mínimo de ejemplares constatado, nos proporciona un friso de más de 14 metros de longitud (fig. 8), dimensión excesiva para el marco de una puerta.

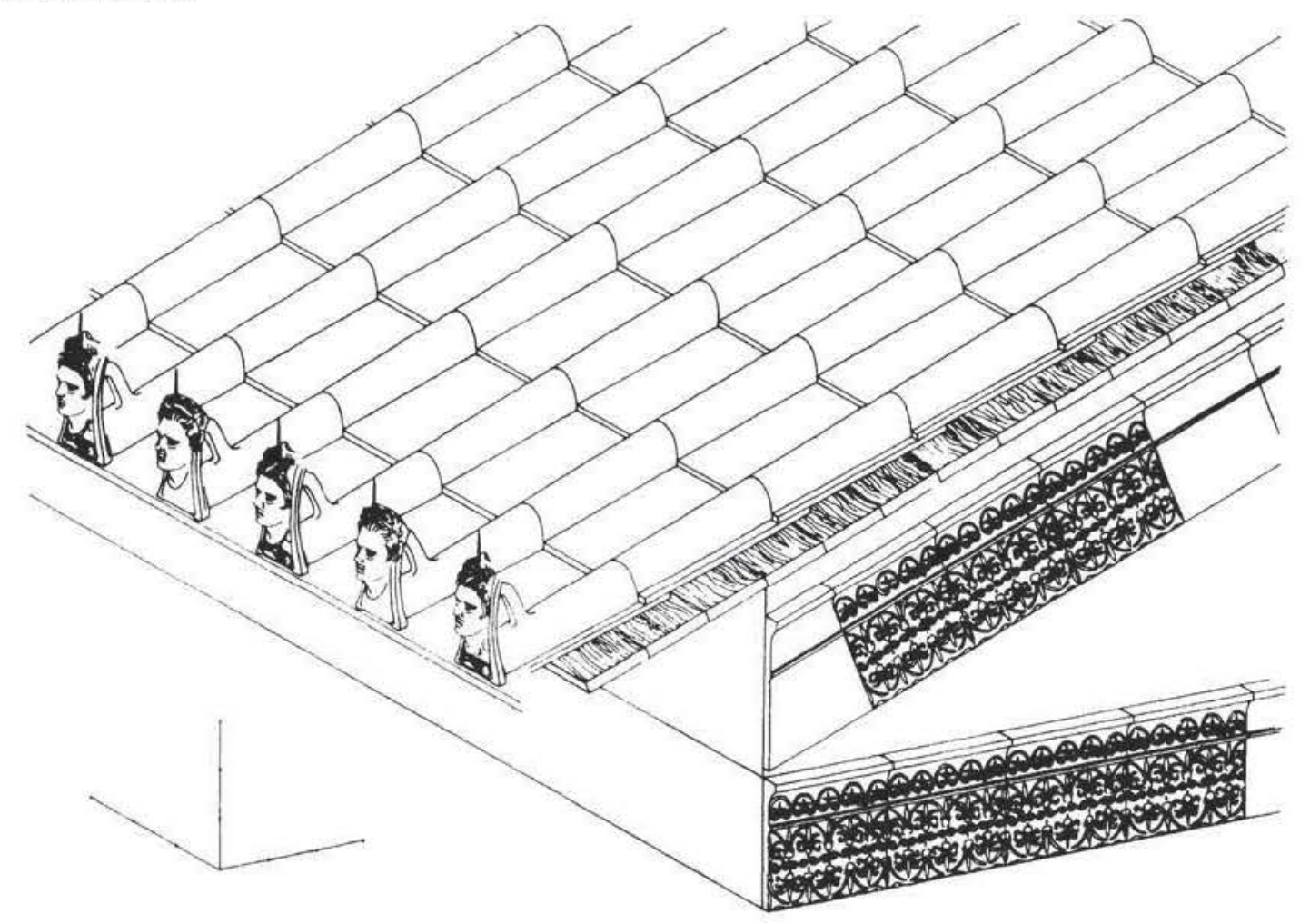

Figura 8.-Propuesta de ubicación de placas y antefijas de La Encarnación. E. 1:10.

En otro aspecto, muy poco se puede aportar de momento, respecto a la policromía que recubría estas placas. En Ardea se han conservado trazas de la decoración en azul y rojo (Andren, 1932); en Cosa se utilizaron el blanco, rojo, amarillo y negro; restos de rojo se han reconocido en las palmetas circunscritas de Cività Castellana; rojo y negro sobre las de Norba, 
y blanco, negro y rojo en las de Segni. En el caso concreto de La Encarnación, quizás debido a que las placas fueron pintadas tras la cocción, tan sólo se pueden señalar posibles trazas de pintura blanca sobre el fondo de la cornisa con palmetas circunscritas del fragmento CE/2404/ 810-1. Desconocemos también si el distinto fondo rojo o marrón de las placas implicaría alguna modificación en la coloración, hecho éste que creemos bastante improbable.

En cualquier caso, es también muy interesante observar la interpretación ibérica del tema de las palmetas circunscritas sobre el ábaco de un capitel de pilastra hallado en Elche (García y Bellido, 1943,63), cuyos escultores dada la coetaneidad con las placas de terracota que aqui analizamos pudieron inspirarse en ejemplares similares. Esta relación se puede hacer extensiva al tratamiento de algunos elementos arquitectónicos (ovas de capiteles por ejemplo) que encuentran una interpretación muy similar en numerosos monumentos ifunerarios? de plena época ibérica.

\section{ANTEFIJAS}

\section{Descripción}

Los fragmentos de las nueve antefijas hasta ahora localizados se encuadran dentro de los tipos de sátiros y ménades básicamente caracteristicos de los siglos III-II a.C. Todas ellas carecen del nimbo estrigilado, rasgo éste caracteristico de las producciones coroplásticas del período inmediatamente anterior e incluso en parte de éste.

Tipo I (fig. 9). Cabeza de sátiro joven e imberbe con corona de hojas de hiedra y un grueso corimbo en el centro de la frente que condiciona en parte el desarrollo de los cabellos sobre la frente. Nebris anudada bajo el cuello. La reconstrucción integral del tipo a partir de los diversos fragmentos conservados permite determinar unas dimensiones en torno a los $24 \mathrm{~cm}$. de altura máxima x $17 \mathrm{~cm}$. de anchura máxima en la base, dimensiones que se hallan dentro de los parámetros establecidos por los paralelos citados más abajo. (Vid por ej. Gabii, 20,8 x 15,2 cm.; Lavinium, 22,5 x $15 \mathrm{~cm}$.; MNR, Tipo 36, n.127, 23,5 x 16,7 cm.)

1. N. ${ }^{\circ}$ Inv. 0001/812-1 (fig. 10). Circunstancias y fecha del hallazgo: desconocidas, depósito antiguo del museo de la Soledad. Un dibujo de esta pieza fue publicado por Lillo Carpio, El poblamiento ibérico en Murcia, 1981, p. 31,8 junto a otras piezas de La Encarnación (1,3,6,7 y 11), como procedente del Santuario del Recuesto (Cehegín). Nuestras recientes excavaciones han contribuido a precisar y corregir el lugar de hallazgo. LMax. $141 \mathrm{~mm}$.; AMax. $101 \mathrm{~mm}$.; GMax. $68 \mathrm{~mm}$. Bastante erosionado ha perdido gran parte de la nariz, boca, ambas sienes, e incluso parte del mentón. Dentro del primer grupo es el ejemplar más completo. Rostro de forma ligeramente ovalado, con frente lisa y baja, las órbitas oculares profundas, con los párpados destacados con grueso listel. Nariz ancha y corta, boca semiabierta con labios gruesos y carnosos, levemente despegados. Cabello levantado hacia arriba con mechones cortos y apuntados. En la frente, destacan los mechones centrales simétricamente opuestos.

2. N. Inv. 2000/812-1 (fig. 11). Circunstancias y fecha del hallazgo: campaña de limpieza, INEM, 1991-1992. Limpieza superficial ladera este. LMax. 94 mm.; AMax. 88,7 mm.; GMax. 52,3 mm. Excelente estado de conservación salvo un pequeño desconchado bajo la boca, sobre el mentón, y pérdida de parte de la nariz. Seguramente procede del mismo molde o uno casi idéntico al anterior y permite completar la descripción de la pieza anterior. La frente aparece recortada por encima de las órbitas oculares por lo que se ha perdido toda la 

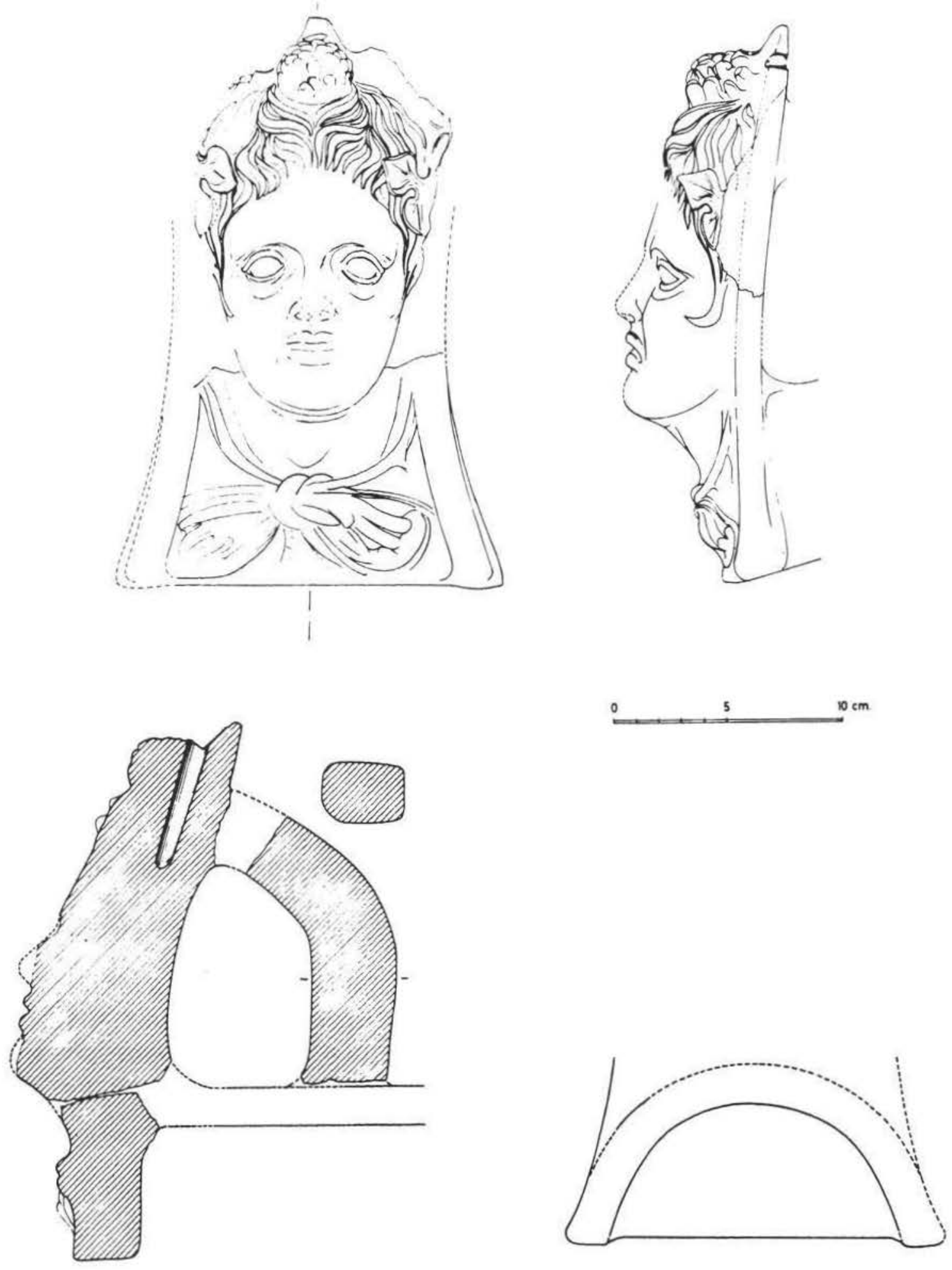

Figura 9.--Propuesta de restitución de la antefija con cabeza de sátiro de La Encarnación, a partir de los fragmentos conservados. E. 1:3. 
cabellera aunque se conserva casi integro el rostro. Fste presenta rasgos físonomicos bicn modelados con mentón redondeado y algo sobresaliente. Los ojos almendrados con parpados destacados se insertan en una profunda cavidad ocular. Las cejas se resaltan tan sólo mediante un ligero abultamiento, mientras que nada se conserva de los pabellones auriculares. La nariz corta y ancha con los orificios nasales muy marcados y los labios. que en el ejemplar anterior estaban muy erosionados. gruesos. carnosos y semiabiertos. Mejillas con pómulos redondeados.

3. N."Inv. $2000812-2$. Circunstancias y fecha del hallazgo: campaña del INEM. 19911992. Limpieza de la ladera este. LMax. 78 mm.: AMax. 88.8 mm.: GiMax. 47.9 mm. Buen estado de conservación. Parte superior y remate de antefija con restos del cabello formado por mechones cortos y ondulados dispuestos de forma simétrica y opuesta desde el centro de la frente donde se inserta una protuberancia, fruto o cormbo. Orificio para insertar el menisc/hus.

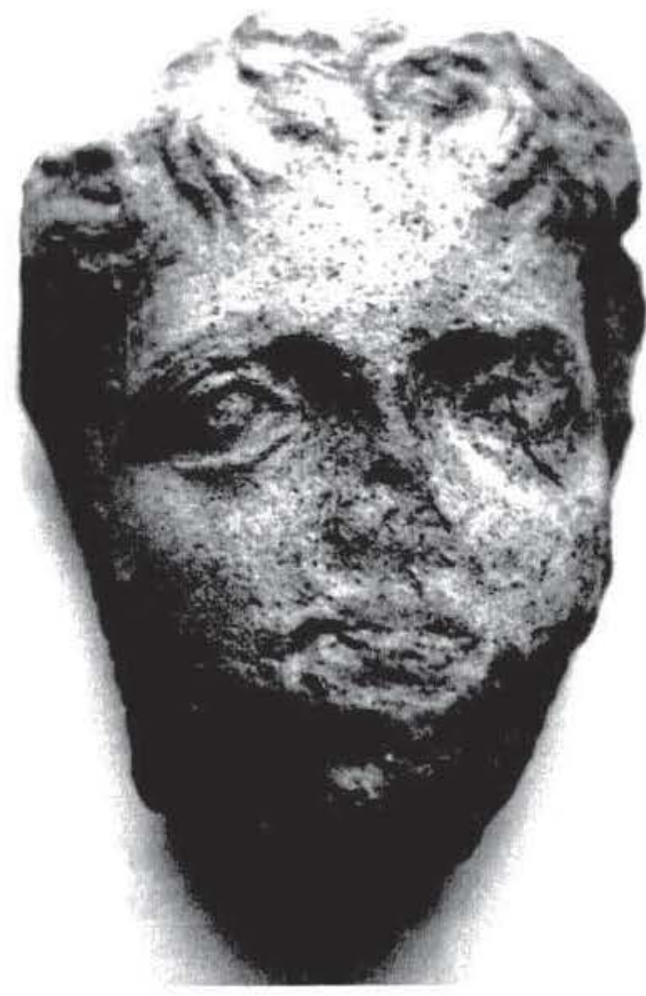

Figura 10.-Antefija con cabeza de sátiro hallada en La Encarnación (A-1.0001/812-1).

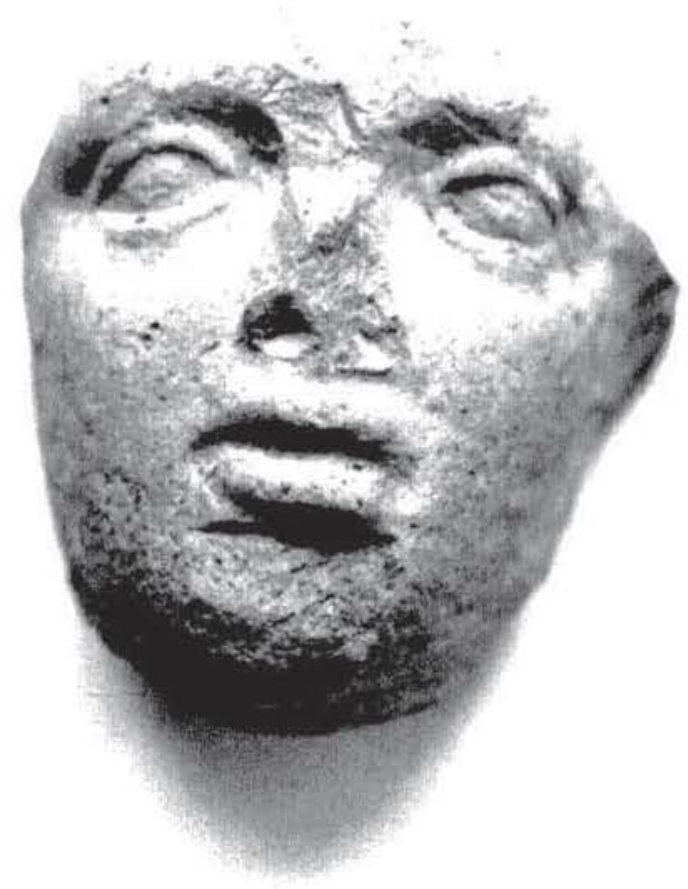

Figura 11. Antefija con cabeza de sátiro hallada en La Encarnación (A-2. 2000/812-1).

4. N. ${ }^{\circ}$ Inv. 4233/812-1 (fig. 12). Circunstancias y fecha del hallazgo: campana oficial del INEM, 1991-1992. En la cuadricula situada al noreste del templo B. LMax. 105,3 mm.; AMax. $96 \mathrm{~mm}$.; Gmax. $53,5 \mathrm{~mm}$. Se conserva la parte superior y de remate de la antefija. 
Cabellera formada por mechones cortos y ondulados que divergen. simetricamente opuestos. en el centro para rodear una gruesa protuberancia circular. quizas un corimbo, a modo de piña. Tras este. apendice triangular liso. y perforación para insertar un vástago metálico o menischus. Una ancha hoja de hiedra con tres pétalos oculta y a la ver recoge los mechones laterales. Tras el existe una profunda perforación circular para engastar una pieza metalica y un apendice lise de forma triangular. En la parte posterior se aprecia la impronta donde se insertaba el asa de union. de seceion aproximadanente cilindrica. con el imbrex.

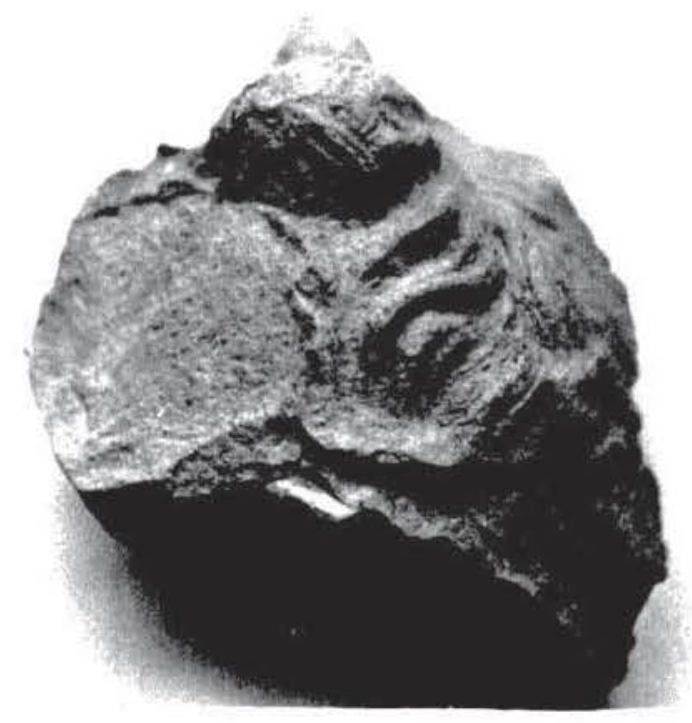

Figura 12. Fragmento de antefija con cabeza de sátiro hallada en La Encarnación (A-4. $4233 / 812-1)$.

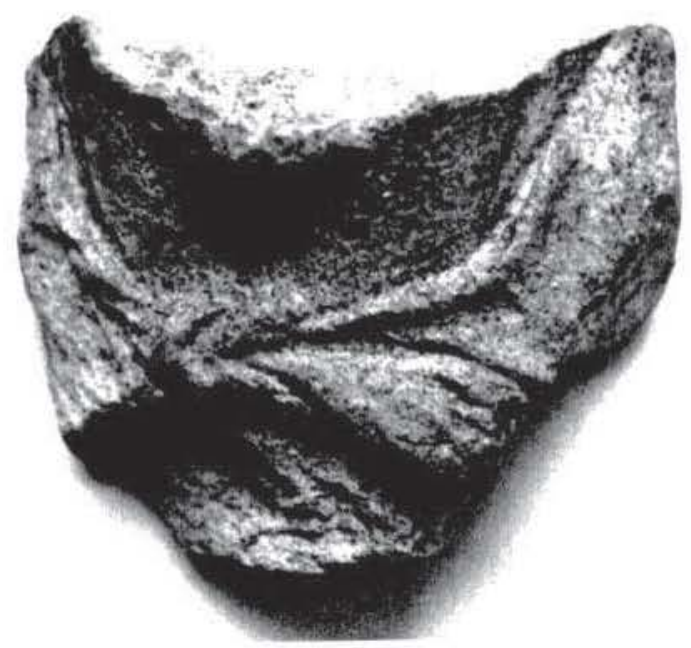

Figura 13. Fragmento de antefija con restos de nehris anudada al cuello de un sátiro, hallada en La Encarnación. (A-6, 5000/812-1).

5. N. Inv. 5145/812-1. Circunstancias y fecha del hallazgo: campaña oficial de julio de 1992. Entorno del templo A. LMax. 78 mm.; A. 145 mm.; GMax. (en la zona del cuello) 40) $\mathrm{mm}$.; Grosor en la base, $21 / 29 \mathrm{~mm}$. Tercio inferior con restos de ancho cuello tras el cual sube la nehris cuyas garras se anudan bajo el mentón. En la parte posterior conserva el arranque semicircular del imbrex.

6. N." Inv. 5000/812-1 (fig. 13). Circunstancias y fecha del hallazgo: campaña oficial del INEM, 1991-1992. LMax. 85 mm.; AMax. 114 mm.; GMax. 44,2 mm. Garras de la nebris anudadas sobre el pecho que rodea el cuello y se levanta por la parte posterior de la cabeza. Conserva en la parte posterior la impronta de unión con el imbrex.

Tipo II (fig. 14). Sátiro o ménade con corona de hojas de hiedra sobre la frente, diadema o tenia anudada en la frente que separa y diferencia los mechones dispuestos horizontalmente de la parte superior y los cortos, apuntados y ligeramente acaracolados del frontal. La factura y 
forma del rostro muy similares a la de la serie anterior, lo que parece indicar un artesano común en la fabricación de ambos moldes.

7. N. ${ }^{\circ}$ Inv. 0001/812-2 (fig. 15). Circunstancias y fecha del hallazgo: recogida superficial en el Cerro de La Ermita por los alumnos del Instituto de Enseñanza Media de Caravaca donde se conserva en la actualidad. LMax. 101,1 mm.; AMax. 104,1 mm.; GMax. 20,5 mm. Bibliografia: una fotografia de esta antefija se reproduce en G. Sánchez Romero, El Campo de Caravaca (Murcia). Bases históricas. Calasparra, 1987, pág. 196.

Restos de una corona de hojas de hiedra sostenidas por una tenia lisa anudada en el centro de la frente que separa los cabellos hirsutos de la región frontal de los de la parietal dispuestos a manera de arquillos.
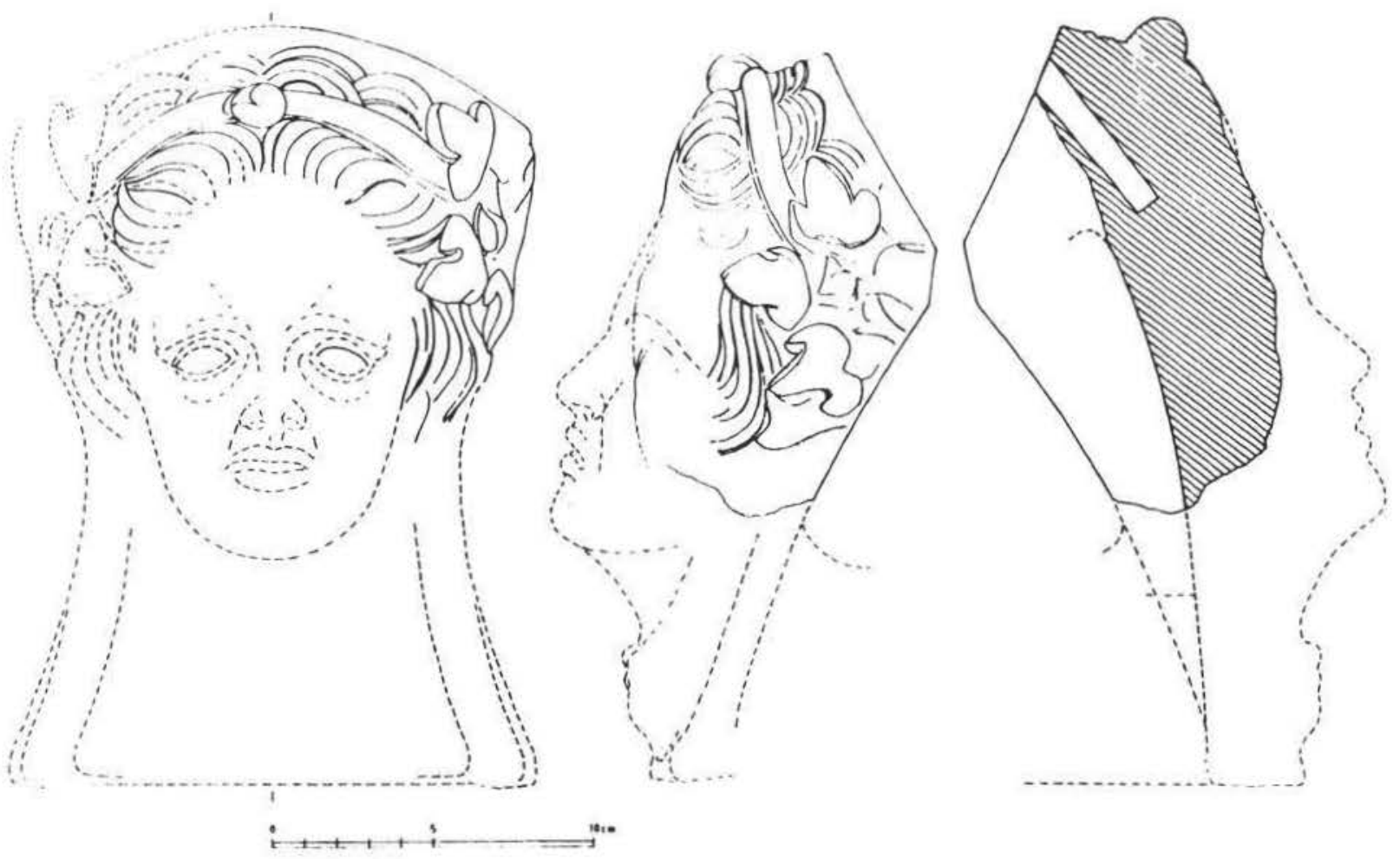

Figura 14.-Propuesta de restitución de la antefija con cabeza de ménade de La Encarnación, a partir de los fragmentos conservados y por analogías con el tipo anterior. E. 1:3.

8. N. ${ }^{\circ}$ Inv. 2000/812-3 (fig. 16). Circunstancias y fecha del hallazgo: campaña oficial del INEM, 1991-1992. LMax. 122,6 mm.; AMax. 125 mm.; GMax. $47 \mathrm{~mm}$. Muy erosionada ha perdido prácticamente la totalidad del rostro y cabello. Se conservan restos de la corona de hojas de hiedra. Perforación longitudinal para la inserción del menischus.

9. N. ${ }^{\circ}$ Inv. 1000/812-1. Circunstancias y fecha del hallazgo: recogida superficial durante la campaña del INEM de 1991-1992. LMax. 104,4 mm.; AMax. 117 mm.; GMax. 38,7 mm. Sobre el cabello corona de hojas de hiedra de forma acorazonada. Perforación longitudinal de $6 \mathrm{~cm}$. para la inserción del menischus. 
Analisis I contologia

Las antefijas de La tncarnacion (figs. 9-16) responden basicamente a las caracteristicas esenciales trazadas para este tipo de produccion coroplástica en Roma y centro de tralia en época helenistica y especialmente durante los siglos 111-11 a.C. Fn ellas ha desaparecido ya el nimbe que rodea la cabeza. al menos en ambientes centro-italicos. desde mediados del siglo 11 y de forma generalizada ya sobre las antefijas del siglo $\checkmark$. sustituido por la corona de hojas y frutos; al tiempo que el modelado y la fisonomia del rostro presentan evidentes referencias clasicistas a obras del siglo IN (Pensabene. 1983.29). Jovenes satiros imberbes y ménades sustituyen a los viejos silenos barbados (Andren, 1940, cexxxiii) que se adornan y a la res se distinguen por la forma de la corona vegetal que recoge los cabellos, la misma forma de estos, e incluso por la presencia o ausencia de la nehris anudada bajo el cuello. Paralelamente, y sobre todo desde el siglo II a.C.. Roma va desplazando los tradicionales centros del área etrusca centro-meridional (Orvieto, (ivita Castellana, ete.) como gran centro productor de material de revestimiento ceramico. Fsta centralización, por asi decirlo de las grandes officinae en Roma, frente a la mayor diversificación de talleres en los principales centros etrusco-laciales durante los siglos IV-III a.C.. que desde ahora se convierte en el centro propulsor de sus propios modelos y tipos a la vez que en el principal centro propagador de los mismos (Anselmino, 1981, 211; Strazzulla, 1977, 47), coincide y a la vez es consecuencia de la utilización de este tipo de recubrimiento cerámico, más allá de los tradicionales edificios sacros, en edificios públicos pórticos, termas, ninfeos, etc. e incluso privados. Paralelamente este proceso concurre con la gran expansión del mundo romano por todo el Mediterráneo y consecuentemente con la apertura de nuevos mercados y un notable aumento de la demanda. Esta generalización conduce a una mayor estereo-

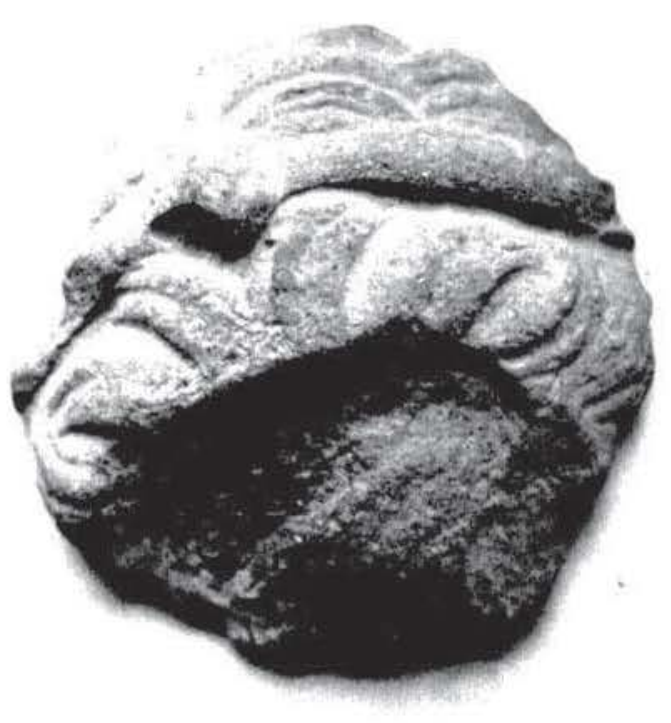

Figura 15. Fragmento de antefija con probable representación de ménade, hallada en $\mathrm{La}$ Encarnación $(\mathrm{A}-7.0001 / 812-2)$.

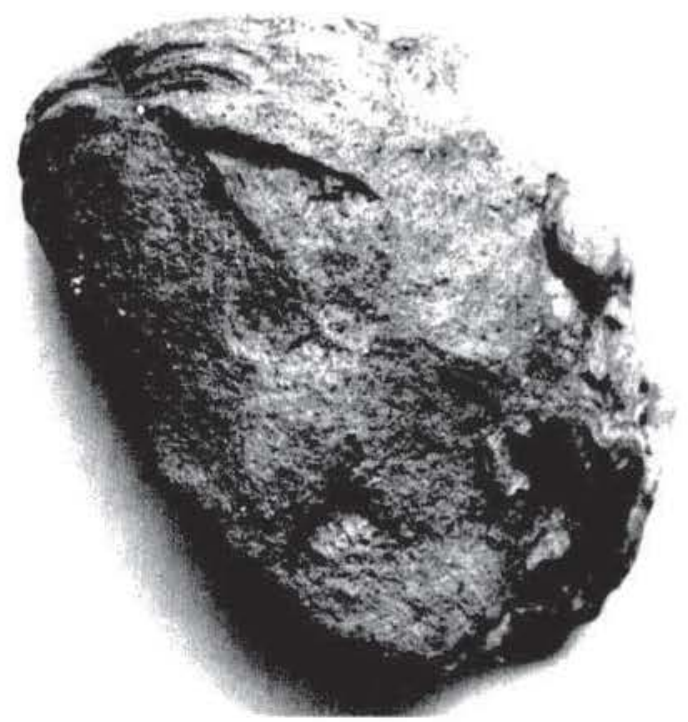

Figura 16. Fragmento de antefija con probable representación de ménade, hallada en La Fncarnación (A-8. 2000/812-3). 
tipación de los modelos, con la consiguiente pérdida de calidad y degeneración en el proceso de producción, que toman como base y principal motivo ornamental el uso de la palmeta de inspiración clásica. En este sentido son muy significativos los hallazgos en Vía Gallia y Via Merulana dello Statuto, de los restos de sendas officinae, activas, al menos en parte, durante el siglo 1 a.C., donde se produjeron antefijas, lastra "Campana", tegulue y ladrillos (Anselmino, 1977, 10-11).

Desde finales del siglo II a.C., y sobre todo durante el siglo I a.C. y la primera época imperial, se generaliza el uso de la palmeta como consecuencia de la influencia cada vez mayor de los talleres neo-áticos sobre la decoración coroplástica, y desaparecen casi por completo los tipos anteriores. Son precisamente estos tipos los que hallamos mejor documentados en las regiones del norte de Italia de romanización más tardía, donde los tipos más precoces con sátiros y ménades propios de finales del siglo III y la primera mitad del siglo Il están prácticamente ausentes (vid. por ej. Strazzula, 1987, passim).

En consecuencia, es precisamente la propia Roma y su entorno más inmediato la que nos proporciona los paralelos más próximos para las antefijas de La Encarnación (fig. 17). Destaca entre ellos una antefija con cabeza de ménade coronada por una guirnalda de hojas de hiedra y con un grueso corimbo en el centro de la frente, hallada en el Palatino (Vaglieri, 1907, 273, f. 17). Dentro de la misma corriente, aunque de características algo distintas, es otra antefija hallada entre los templos C y B de Largo Argentina con corona de corimbos y hojas y la nebris anudada bajo el cuello (Marchetti-Longhi, 1934, 305, f. 18), hallada en un estrato sellado por el pavimento de tufo construido cuando la fundación del templo B, en torno al 100 a.C. Parece corresponder a la decoración del templo $\mathrm{C}$, si bien no se puede precisar si pertenece al aparato figurativo original de la primera mitad del siglo III a.C. o más bien, a una restauración posterior datada en torno al 179 a.C. (Strazzula, 1977, 47), fecha ésta última que consideramos más probable.

En líneas generales, la nebris anudada bajo el cuello suele aparecer en antefijas con cabeza de sátiro joven bien con corona de corimbos y hojas (MNR, tipo 32), bien con corona reducida (tipo 36-38) o a veces sin ella (tipo 39), fechadas en su mayor parte a finales del siglo III o en el siglo II a.C.

La unión de sátiros y ménades con una cronología amplia similar y en un mismo conjunto se identifica asociado a los templos D, B y de Júpiter, en Cosa, con nebris anudada en la base del cuello, en el sátiro. Ambas figuras se destacan de una concha o nimbo redondeado sobre el que se desarrolla serpenteante un tallo con zarcillos, flores estrelladas y hojas acorazonadas que brotan desde acantos situados en los ángulos (Richardson, 1960, 187). De esta misma ciudad, concretamente de la reparación del templo de Júpiter, procede otra antefija con cabeza exenta de joven sátiro, con la nebris anudada bajo el cuello, datada en torno al año 100 a.C. (Richardson, 1960, 177, lám. XXII, 1-2).

En el santuario de Iuno en Gabii las terracotas con cabeza de joven sátiro, algunas de estrecho parentesco con nuestros ejemplares, proceden en su mayor parte de la favissa II y se encuadran dentro de Grupo VII:3, fechándose entre el 150 y el 100 a.C. (Dupré, 1982, n. ${ }^{\text {os }}$ 295-299, lám. XXVIII). Una de ellas, concretamente, presenta el busto de un joven sátiro imberbe, cubierto por un velo y decorado con una diadema de factura muy similar a nuestra pieza n. $^{\circ} 8$ (Dupré, 1981, fig. A 91, 44). En esta misma corriente se inscriben también algunas antefijas del santuario de Diana en Nemi, depositadas en el Museo de Nottinghan (Melis y Serra, 1987, fig. 3 y MacCornick, 1983, 31). En este mismo contexto hay que ubicar también 
las antefijas con cabeza de sátiro con corona «di corimbi e foglie» asociadas a antefijas con cabeza "Melonenfrisur» y corona de "pampini e grappoli» del santuario de luno Lacina en Norba, fechadas en la segunda mitad del siglo III-inicios del siglo II a.C. (Pensabene, 1983, 9193; Savignoni y Mengarelli, 1903, 248, fig. 16). Similar a ésta última es también una antefija del depósito votivo di Campetti, en Veii (Vagnetti, 1971, n. 8, lám. II, pág. 28). Tivoli ha procurado una antefija con cabeza de ménade adornada con una diadema y corona de hiedras y corimbos, datada en el siglo II a.C. (Faccenna, 1957, 131, f. 9). También Pompeya nos ofrece algunas antefijas con cabeza de sátiro joven e imberbe, sonriente, con la nebris anudada sobre el pecho y con cabello de mechones cortos y ondulados adornados por pequeñas hojas (Ambrosio y Borriello, 1990, n. ${ }^{\circ} 77$ ). Algo más alejados en cambio del modelo utilizado en La Encarnación se hallan las antefijas con cabeza de joven sátiro de Arezzo, coronados con racimos y hojas de hiedra (Pernier, 1920, 200) y de Lavinium, con cabeza velada de joven sátiro, sonriente, cabellera de gruesos mechones irregulares y las garras de la nebris anudadas en la base del cuello (Mazzolani, 1975, 179).

El modelado del rostro, los ojos, labios gruesos e incluso la forma de los mechones puntiagudos del cabello de las antefijas con corimbos es muy similar a algunas de las cabezas votivas de algunos santuarios etruscos, como por ejemplo una cabeza masculina del tempio del Manganello, en Cerveteri donde se constata el paso desde las fórmulas post-clásicas o protohele-

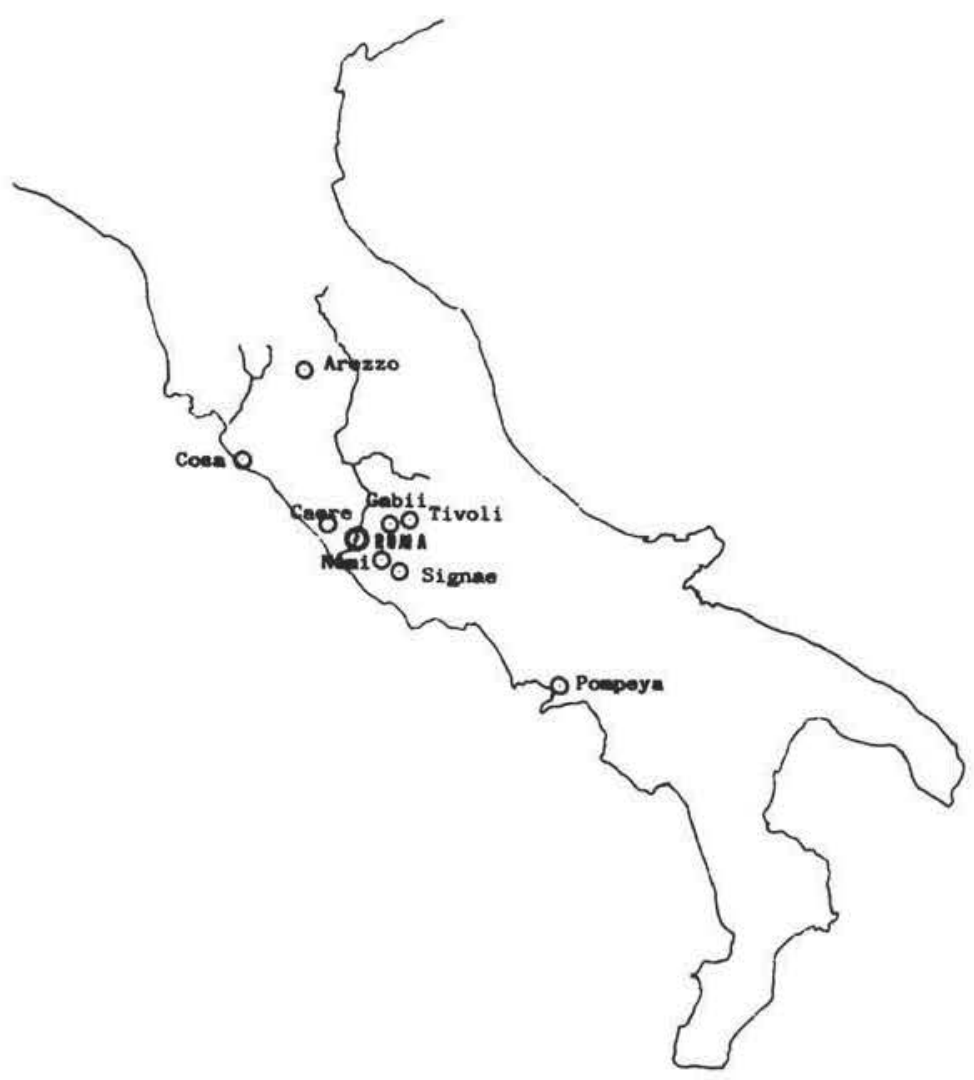

Figura 17.-Distribución geográfica de los principales paralelos para las antefijas con sátiros y ménades de La Encarnación. 
nísticas de los ejemplares velados más antiguos que perduran durante la segunda mitad del siglo IV y todo el siglo III a.C., a la corriente clasicizante del último helenismo que sigue modelos lisípeos para los ejemplares masculinos. (AA.VV., 1985, 40, depósito 1.26-A5) o también de algunas de las cabezas votivas de Carsoli (Cianfarani et alii, 1978, 389).

Es también muy interesante destacar el hallazgo en las excavaciones de Largo Argentina de varios menischi en forma de piezas metálicas de bronce con uno de sus extremos curvado en espiral que, aplicados sobre el remate superior de la antefija, evitaban que ésta pudiera ser derribada por los pajarillos y palomas. Las perforaciones para colocar estas piezas se han constatado en varias de las antefijas de la Encarnación.

La aparición de las terracotas (antefijas y placas de revestimiento) en la Encarnación, con toda certeza importados por vía marítima desde los centros de producción centro-itálicos (probablemente de la misma Roma), nos lleva a replantear ciertos hallazgos submarinos de material arquitectónico cerámico que tradicionalmente han sido interpretados como material perteneciente a la propia nave. Muy significativo en este sentido es el hallazgo de Porto Venere, donde entre grandes tejas romano-republicanas se pudo reconocer un imbrex con antefija de características similares a los hallados en los templos etrusco-itálicos de los siglos III-II a.C. (Lamboglia, 1965, 246).

\section{VALORACIÓN}

El principal problema estriba en determinar las causas que provocan la llegada de estos productos a este territorio del interior en unas fechas tan tempranas y en qué contexto histórico se insertan. En este sentido, es preciso señalar que La Encarnación no es un caso aislado en el contexto general de la romanización de los últimos siglos de la República, sino que se inserta en una serie mayor de poblados y santuarios ibéricos que, tras las primeras escaramuzas de conquista, a la que muy pronto sigue la rebelión de los pueblos hispanos que se produce a comienzos del siglo II a.C., tan sólo sofocada por la actitud firme y decidida de Catón enviado a la península con poder proconsular en el 195 a.C., perviven, algunos incluso con un renovado esplendor, durante al menos los siglos II y I a.C., mientras que otros parecen sufrir una destrucción sistemática y abandono en los últimos años del siglo III a.C. y sobre todo los años iniciales del siglo II a.C. (Coimbra del Barranco Ancho, Amarejo, etc.). Aquí hay que ver claramente una apuesta decidida o toma de partido de determinados núcleos poblacionales por la causa romana, quizás incluso más en contra de su propios vecinos que de la vieja potencia púnica, ya vencida. En esta situación se hallan, junto a La Encarnación, poblados del significado y envergadura de Bolbax, auténtica llave de paso en el curso medio-alto del Segura y con una clara tradición habitacional que remonta al menos hasta finales de la Edad del Bronce, y cuya pervivencia en época romano-republicana se refleja en los restos de pavimentos de opus signinum decorados con teselas blancas - los únicos que conocemos fuera del área costera y en ambiente plenamente ibérico- hallados sin contexto tras el expolio sistemático del Cerro; y del Verdolay, con una topografia y situación muy similar, flanqueando el curso medio del Segura donde los ajuares de la necrópolis muestran una significativa continuidad hasta al menos el tercer cuarto del siglo II a.C., para decaer posteriormente en clara coincidencia con la revitalización económica del tramo costero del entorno de Carthago Nova y especialmente de sus minas, que probablemente absorberian, junto a esclavos de guerra, una abundante mano de 
obra procedente de estas regiones del interior. Pero el paralelo más significativo es el del Cerro de los Santos, donde fueron hallados los restos de un templo tetrástilo, jónico, seguramente sin podium, con alzados de opus quadratum y rebancos adosados a las paredes, de caracteristicas y cronología muy similares a La Encarnación.

Desde el punto de vista tipológico es muy difícil precisar la planta del templo al que se asocia este material cerámico. En ámbitos centro-itálicos, los materiales con estas características aparecen en edificios de culto construidos parcialmente en piedra (basas, fustes y capiteles), y entablamento, con arquitrabe y friso junto al frontón, en madera. Estos últimos ocultados exteriormente por placas de revestimiento. De esta forma, en una primera aproximación, vinculamos el material cerámico con nuestro templo A, de menores dimensiones y de tipología más sencilla, tal vez un templo in antis con dos columnas entre ambas o un simple próstilo tetrástilo (fig. 18), pero el posterior incremento del número de placas en las campañas siguientes, nos ha hecho dudar ya de esta primera adscripción, ya que identificando cada fragmento como perteneciente a una placa distinta de $23,2 \mathrm{~cm}$. (hemos intentado recomponer el máximo de fragmentos y determinar el número máximo de placas) y multiplicando por el total de 61 fragmentos, considerando que cada pieza recuperada corresponde a una placa distinta, nos proporciona un total de algo más de $14 \mathrm{~m}$. (14,152 m.) lo que excede en casi 10 metros la anchura total del frontal del templo A (de 5,10 m.) e implicaría la continuación del friso sobre los lados laterales del edificio (algo que se ha sugerido para algunos templos itálicos) o por los vértices del frontón. Por otra parte no se ha registrado ningún fragmento de esquina, que se pueda relacionar con un posible marco de puerta (como se ha señalado para los templos itálicos de Pyrgi o Cosa) o que pueda vincularse con el revestimiento de un posible frontón. Al mismo tiempo, el hecho de que el templo A presente una orientación casi subordinada por la existencia del templo B, y distintos problemas de tipo arquitectónico, podrían justificar la existencia de una primera fase en este templo, tal vez como un simple tetrástilo, anterior a la última monumentalización como templo, jónico, octóstilo y pseudodíptero.

De cualquier forma, la cronología precoz de este primer conjunto implica sin duda un primer proceso de monumentalización de las estructuras ibéricas. Ahora bien es muy difícil, en un ámbito eminentemente ibérico como el que nos hallamos, aceptar un encargo directo por parte del régulo u oligarquía local de un edificio ya terminado y que sigue en todo los patrones la arquitectura templar itálica. Sabemos por otra parte del intento de asimilación, al menos formal, por parte de los reguli o aristocracias locales, con los generales o personajes romanos. Este fenómeno se manifiesta claramente en la adopción de formas externas, cual es el vestuario, con que algunos de estos personajes quieren ser representados, en las esculturillas o exvotos que se ofrecen en los principales santuarios del sureste (el ejemplo más significativo nos lo proporcionan los palliati del Cerro de los Santos, aunque algunos exvotos de bronce de procedencia surestina siguen esta misma tradición). Por otra parte este fenómeno de transformación de las viejas estructuras de culto ibéricas, quizás en parte aún de madera, no es un fenómeno exclusivo de La Encarnación o el Cerro de los Santos, sino que se puede también hacer extensivo a otros famosos santuarios como los de La Luz, Despeñaperros, y, siguiendo modelos arquitectónicos distintos, al de Torreparedones, caracterizados todos ellos por la identidad formal de sus exvotos. En la mayor parte de los casos, esta continuidad y sobre todo estas transformaciones de tipo urbanístico, se deben vincular con un apoyo decisivo a la causa romana, que en muchos casos arranca quizás del final de la Segunda Guerra Púnica y, sobre todo, a sus generales y gobernadores, pertenecientes a la más rancia aristocracia senatorial 


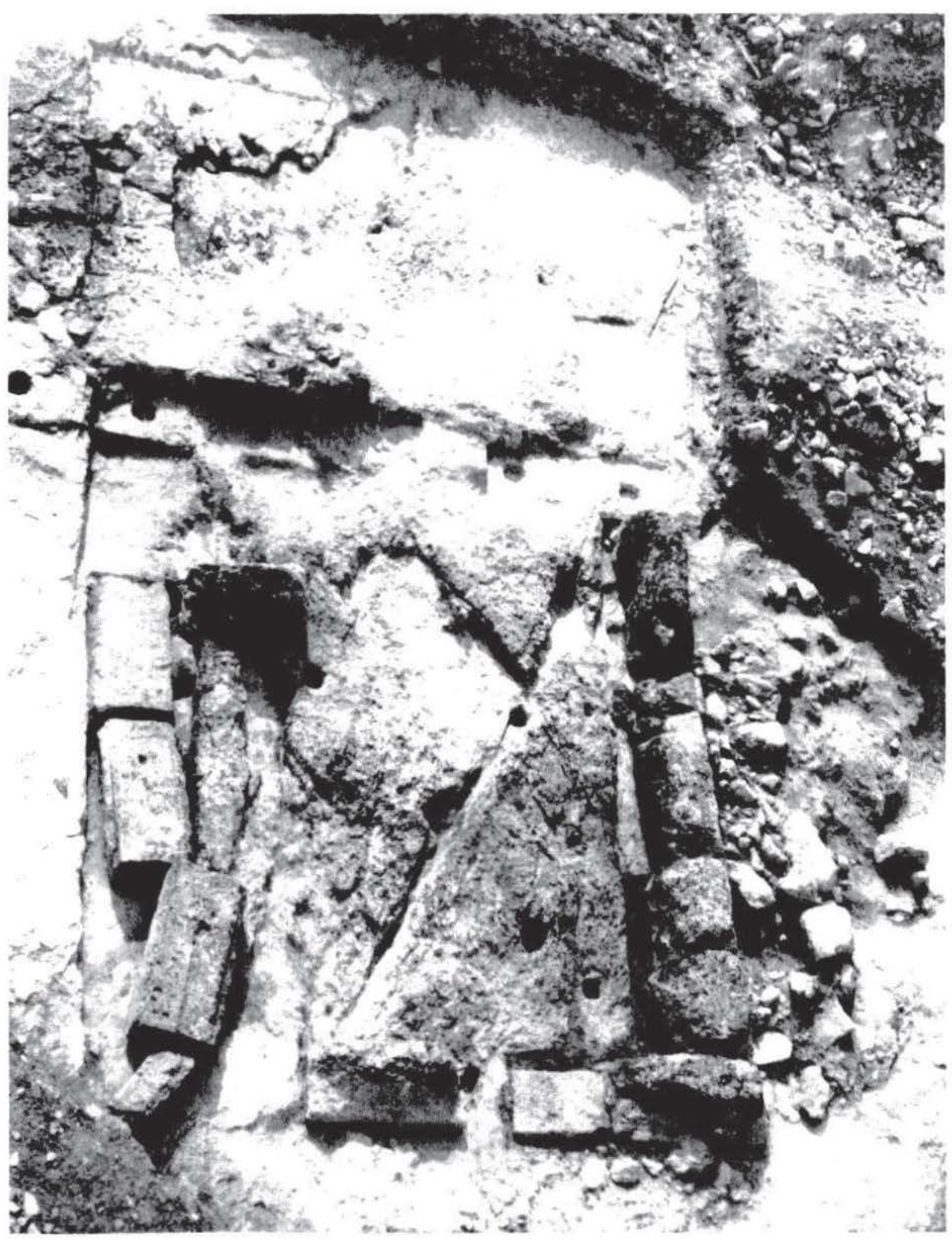

Figura 18. Cimentaciones del templo A del santuario de La Encarnación. 
romana, que con una hábil politica de clientelas han sabido ganarse el respeto y la devoción de los caudillos ibéricos. La politica de conciliación inicialmente puesta en marcha por Escipión es seguida por otros generales cuya actuación deja huella en pueblos o regiones hispanos. Se ha señalado la existencia de regalos por parte de algunos de estos importantes personajes a determinadas ciudades de la Península Ibérica, destacándose sobre todo el caso de L. Mummius con la ciudad de Itálica y tras la toma de Corintho aunque recientemente el epigrafe que servía de base para esta relación ha sido reinterpretado y vinculado con L. Aemilius Paullus Macedonicus (Canto, A., 1983, 227 ss.), personaje que juega un importante papel en un período importante de la conquista y pacificación romana de Hispania, y que desde el punto de vista cronológico estaria más acorde con la cronología posible del material cerámico de la Encarnación. De cualquier forma, actualmente es imposible vincular el desarrollo de esta población durante este periodo con un personaje o familia determinada de los últimos siglos de la República.

Por otra parte es muy interesante relacionar este proceso de monumentalización precoz con un fenómeno similar que se observa en algunas regiones centro-itálicas con anterioridad a la Guerra Social. En Lazio, Saunio y Piceno nos hallamos también con la transformación de viejas estructuras autóctonas que modifican su aspecto original, siguiendo unas normas más o menos precisas y comunes a una amplia zona. Es característica común a la mayor parte de ellos los alzados sobre columnas estriadas, basas áticas sin plinto, capiteles jónicos de cuatro caras (jónico-itálicos) y entablamentos de madera recubiertos por placas de decoración geométrica. En este sentido hay que destacar la presencia constante del capitel jónico de cuatro caras en el conjunto de La Encarnación, aunque matizado con las peculiaridades que le impone la existencia de una tradición anterior en la arquitectura ibérica monumental. Por otra parte un dato también muy significativo, prueba de esa cronologia precoz para La Encarnación, se halla en los restos de pavimento de opus signinum decorado con teselas blancas, que todavía se pueden reconocer frente a la puerta de ingreso a la cella del templo $\mathrm{A}$ y sobre todo en múltiples fragmentos recogidos en los niveles de colmatación depositados junto al lateral oeste del templo $\mathrm{B}, \mathrm{y}$ que encuentra parangón asimismo en muchos de estos santuarios itálicos.

En términos generales, y desde el punto de vista arquitectónico, la adopción de modelos de inspiración itálica o helenística se refleja pues en la utilización de todos estos elementos ornamentales (placas cerámicas o antefijas) o arquitectónicos (capiteles, cornisas, basas, etc.), y sobre todo en la utilización de determinadas plantas que responden a modelos elaborados en ambientes centro-itálicos o del Mediterráneo Oriental (templos A y B), en edificios que se insertan en un espacio (santuario) preexistentes. Sin embargo, a diferencia de los modelos itálicos o helenísticos, aqui no se establece una organización, sistematización y seguramente jerarquización integral del espacio y los edificios no ocupan el centro o eje de complejas composiciones simétricas encerradas en un temenos encuadrado por muros regulares e intimamente integradas en el paisaje, al modo de las grandes creaciones helenísticas. Por el contrario el edificio templar se ubica por razones cultuales que de momento desconocemos, como por ejemplo en el Cerro de los Santos, en un extremo del propio santuario o descentrado en relación a éste, aunque hay que intuir en esta ubicación precisa un intento de suplantación o mejor de continuidad del viejo emplazamiento de culto, pero con materiales y nuevas fórmulas constructivas.

En consecuencia, y a partir de los hallazgos de La Encarnación, conjugados con las referencias y datos de otros santuarios ibéricos, podemos hablar de una continuidad cultual y religiosa de algunos de los más antiguos santuarios ibéricos desde los primeros momentos de la romanización que a su vez coincide con un proceso de monumentalización de los antiguos recintos sacros. 


\section{BIBLIOGRAFÍA}

AA.VV., 1981: Enea nel Lazio. Archeologia e mito. Roma.

AA.VV., 1985: Santuari d Etruria. (Cat. Mostra Arezzo 1985). Milano.

Ambrosio, A. DE y BORRIEllo, M., 1990: Le terrecotte figurate di Pompei. Roma.

Andri:n, A., 1932: Terrecotte di Ardea. Acti Inst. Rom. Reg. Sueciae, II, 98-117.

ANDREN, A., 1940: Architectural Terracottas from Etrusco-Italic Temples. Lund.

AnStLmino, L., 1977: Terrecotte architettoniche dell antiquarium comunale di Roma. I. Antefisse. Roma.

ANSELMINO, L., 1981: Le antefisse fittili dal I a.C. al Il d.C. En: Merci, mercati e scambi nel Mediterraneo. Società romana e produzione schiavistica, 209-218.

ARDEA. 1983: Imagini di una ricerca. Ministero per i beni culturali e ambientali, De Luca Ed. Roma.

Bedello, M., 1990: Botteghe artigiane a Capua, En: Artigiani e hotteghe nell 'Italia preromana. Studi sulla coroplastica di area etrusco-laziale-campana. Roma.

Breitenstein, N., 1941: Catalogue of terracottas Cypriote, Greek. Etrusco-italian and Roman. Danish National Museum.

CAnto, A., 1983: Un nuevo documento de Paulo Emilio en la Hispania Ulterior: CIL, I, 546=CIL II, 1119, Reunión sobre epigrafia hispánica de época romano-republicana, Zaragoza, 227-234.

CATALDI, M., 1986: Un maestoso tempio per gli dei: l'"Ara della Regina» ed i recenti interventi. La decorazione architettonica. In: Gli Etruschi di Tarquinia, Modena, 357-364.

Cianfarani, V., Franchi, L. y La Regina, A., 1978: Culture adriatiche antiche di Abruzzo e di Molise, 2 vols. Roma.

COLINI, A. M., 1935: Notizia di un poco noto gruppo di terrecotte architettoniche etrusche dalla III fase. Studi Etruschi, 9, 95-106.

DELBRUCK, R., 1903: Das Capitolium von Signia. Roma.

DELBRUCK, R., 1907-12: Hellenistiche Bauten in Latium. Strasbourg.

Dupré, X., 1981: En. AA.VV.: Enea nel Lazio. Archeologia e mito. Roma.

DUPRÉ, X. 1983: Terracotas arquitectónicas. En: M. Almagro (Ed.), El santuario de Juno en Gabii, CSIC, 131-194.

Facenna, D., 1957: Tivoli (Piazza D.Tani). Necropoli del V-IV secolo av. Cr. rinvenuta durante i lavori di ampliamento della Cartiera Amicucci. NSc.

FAlConi AmORELli, M. T., 1977: Todi prerromana. Catalogo dei materiali conservati nel Museo Communale di Todi. Perugia.

FORTE, M., 1991: Le terrecotte ornamentali dei templi Lunensi (Catalogo delle terrecotte architettoniche a stampo conservate al Museo Archeologico Nazionale di Firenze). Istituto Nazionale di Studi Etruschi ed Italici. Biblioteca di Studi Etruschi, 22, Firenze.

FORTE, M., 1992: Le terracotte architettoniche di Luni: la ricomposizione del rivestimento fittile del Grande Tempio e del Capitolium, En: La coroplastica templare etrusca fra il IV e il II secolo a.C., 185 ss.

GARCIA Y BELLIDO, A., 1943: La dama de Elche y el conjunto de piezas arqueológicas reingresadas en España en 1941. Madrid.

GulliNI, G., 1980: La cultura architettonica di Locri Epizefirii. Taranto.

Johnson, J., 1935: Excavations at Minturnae. Monuments of the Republican Forum. Philadelphia.

LAmboglia, N., 1965: Una nave del III o II secolo a.C. nelle acque di Porto Venere? RSL, XXXI, 3, $243-252$.

Libertini, G., 1921: Le decorazioni fittili di un tempio italo-etrusco sul colle di Telamonaccio, Atti della Pontificia Accademia romana di Archeologia, 2. serie 15, 135-178.

Mac Cornick et Alil A. G., 1983: Mysteries of Diana. The Antiquities from Nemi in Nottinghan Museums. Architectural Terracottas, por T.F.C. BLAGG. Nottinghan.

MARChETtI-Longhi, G., 1932: Gli scavi del Largo Argentina. BCAR, LX, 299 ss.

Mazzolani, M., 1975: Terrecotte architettoniche (A). In: Lavinium II. Le tredici are. Roma, 175-179. 
MILIS. F., y SI:RRA RIDGWAY, F. R., 1987: «Mysteries of Diana». Sulla nuova esposizione dei materiali nemorensi nel castle Museum di Nottinghan, Archeologia Laziale, VIII, 218-226.

MIL.ANI. L. A., 1885: I frontoni di un tempio tuscanico scoperti in Luni, Museo Italiano di Antichità Classica, I, Firenze, 89-112.

NiRO, A. DE, 1980: Pietrabbondante. Terrecotte architettoniche. I Fase. In: Sannio, Pentri e Frentani dal Vl al I sec. a.C. Roma, 162-164.

MNR. $=$ Vid. Pensabene y Sanzi di Minzo, 1983.

PinSAbline, P., y SAnZI dI Minzo, M. R., 1983: Museo Nazionale Romano. III.l. Le Terrecotte. Antefisse. Roma.

PI:RNII:R, L., 1920: I. Arezzo. Ricerche per la scoperta delle antichi mura urbane laterizie nei terreni di «Fonte Pozzolo» e Catona. NSc., 167-215.

PIRGY, 1970: AA.VV.: Pyrgi. Scavi del Santuario etrusco (1959-1967), NSc., Il Suppl. al vol. XXIV. Roma.

RAmallo, S., 1992: Un santuario de época tardo-republicana en La Encarnación, Caravaca, Murcia, Cuadernos de Arquitectura Romana, 1, 39-65.

RIChardson, L., 1960: Cosa II. The Temples of the Arx. The Architectural Terracottas. MAAR, XXVI, 151-300.

RoSEl.LE, 1976: Gli scavi e la mostra. Soprintendenza archeologica della Toscana. Pisa.

SAVIGNONI, L. y MENGARELLI, R., 1901: Relazione sopra gli scavi eseguiti nell'estate dell'anno 1901. $N S c ., 514$ ss.

SAVIGNONI, L., y MENGARELLI, R., 1903: V. Norba. Relazione sopra gli scavi eseguiti a Norba nell'estate dell'anno 1902. NSc., 229-262.

SteFANI, E., 1944-45: Ardea. Saggi nella necropoli e nell'area del tempio sopra l'acropoli, NSc., 81-104.

STEFAnI, E., 1951: Una serie di lastre fittili del santuario etrusco di Veio. Arch.Class., 3, 138-146.

Stopponi, S., 1979: Terrecotte architettoniche del santuario di Punta della Vipera. Nuovi Quaderni dell'Istituto d'Archeologia dell'Università di Perugia (Studi in onore di Filippo Magi), 1, 249-270. Perugia.

Strazzula, M. J., 1977: Le terrecotte architettoniche nell'Italia centrale, Caratteri dell'ellenismo nelle urne etrusche, Suppl. I de la rivista Prospettiva, 41-49.

Strazzula, M. J., 1981: Le produzioni dal IV al I a.C., Merci, mercati e scambi nel Mediterraneo. Società romana e produzione schiavistica, Roma-Bari, 187-207.

StrazzUla, M. J., 1987: Le terrecotte architettoniche della Venetia romana, contributo allo studio della produzione fittile nella Cisalpina (II a.C.-II d.C.). Studia Archeologica, 44. Roma.

TALAMONE, 1982: Talamone. Il mito dei sette a Tebe. Catalogo della Mostra. Firenze.

TORELlı, M., 1967: Terza campagna di scavo a Punta della Vipera (Santa Marinella). Studi Etruschi, XXXV, 97-110.

TORElLI, M., 1974: La situazione in Etruria, Hellenismus im Mittelitalien, Gottingen, 101 ss.

VAGLIERI, D., 1907: III. Roma. Nuove scoperte nella città e nel suburbio. NSc., 261 ss.

VAGnetti, L., 1971: Il deposito votivo di Campetti a Veio (materiale degli scavi 1937-1938). Firenze.

WIKANDER, Ö., 1986: Sicilian Architectural terracottas. Acta Instituti Romani Regni Sueciae, Series n. 8. XV, Stockholm. 